\title{
تاثير العواصف النارية عبر وسائل التواصل الاجتماعى على اتجاهات المستهلك دراسة تطبيقية على سوق المواد الغذائية
}

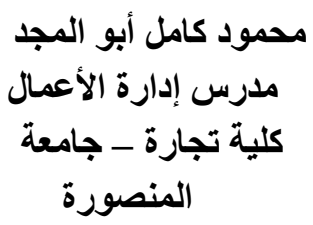

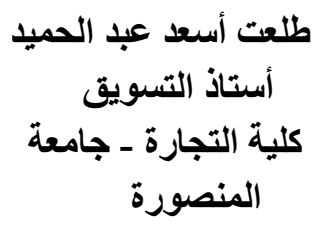

$$
\begin{aligned}
& \text { مصطفى سيد متولى السيد } \\
& \text { طالب دكتور اه } \\
& \text { كلية التجارة - جامعة المنصورة }
\end{aligned}
$$

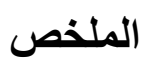

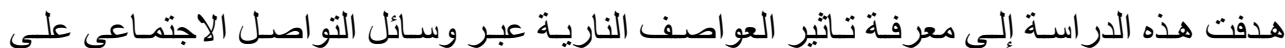

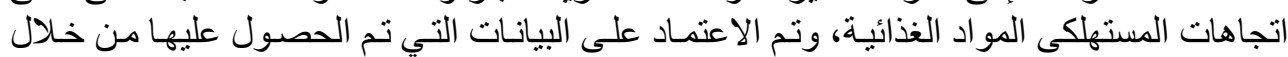

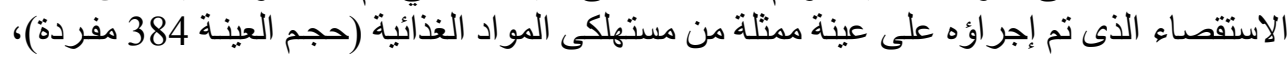

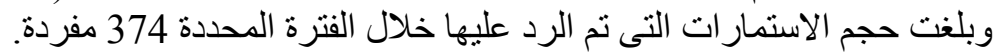

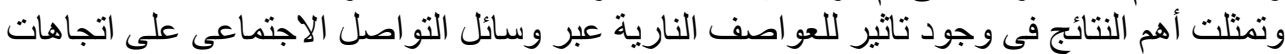
مستهلكى المو اد الغذائية.

\section{Abstract}

This study aimed to know the effect of fire storms through social media on the shift in purchasing intentions when mediating trends of food consumers, and the data obtained through the survey that was conducted on a representative sample of foodstuff consumers (sample size 384 single) was relied on. The volume of the questionnaires that were answered during the specified period reached 374 items.

The most important finding was the effect of consumer trends on the relationship between fire storms through social media and the shift in the purchasing intentions of food consumers.

\section{$\ddot{d} 0$ مै⿴囗十)}

أن وسائل التو اصل الاجتماعى اليوم لديها قدرة على نشر المعلومـات بشكل

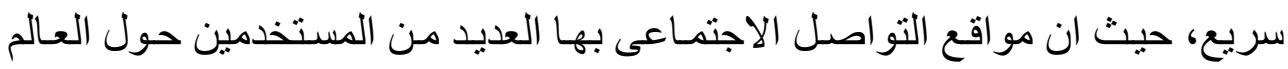

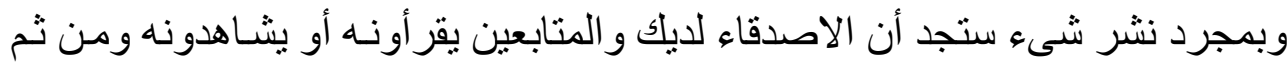

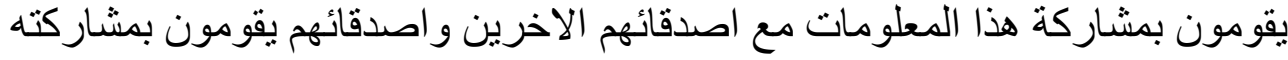

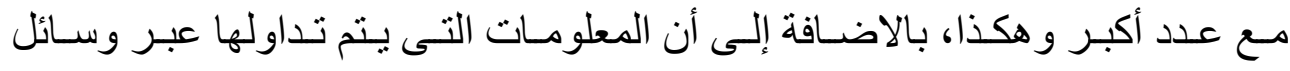




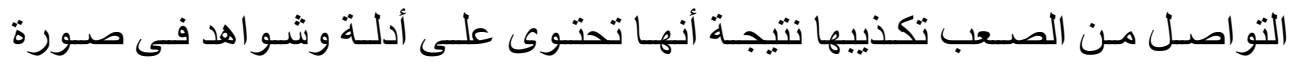

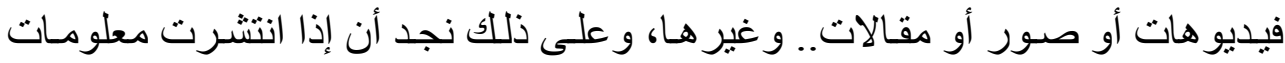

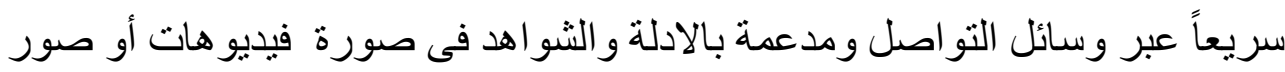

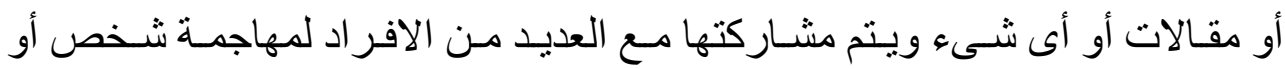

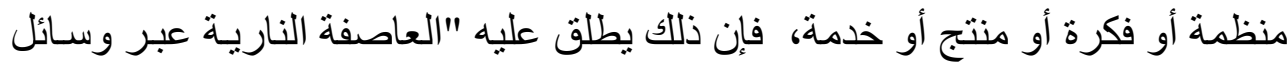

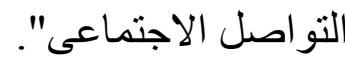

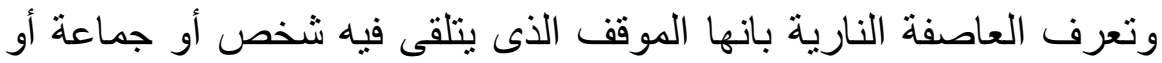

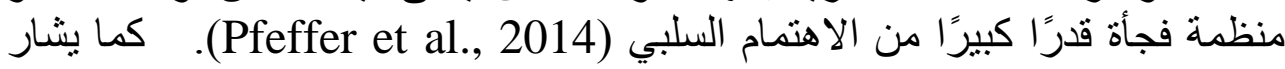

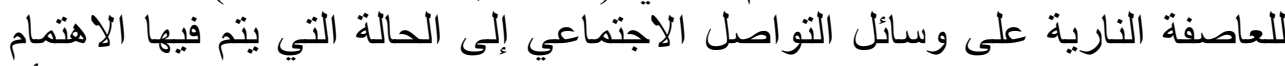

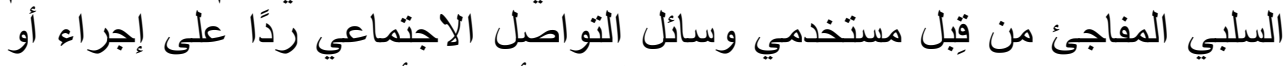

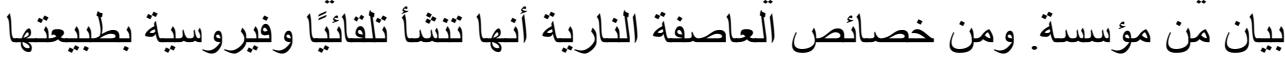

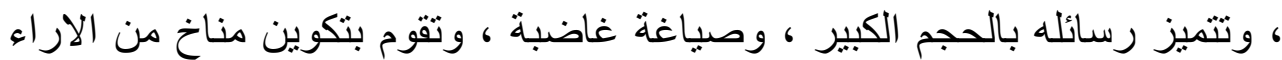
السلبية (Johnen et al., 2018)

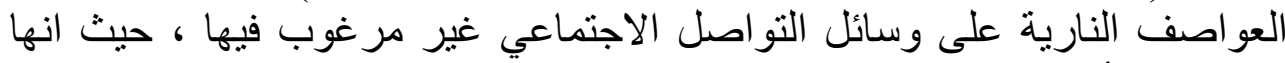

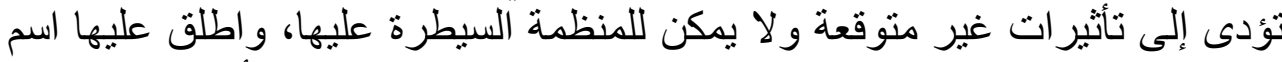

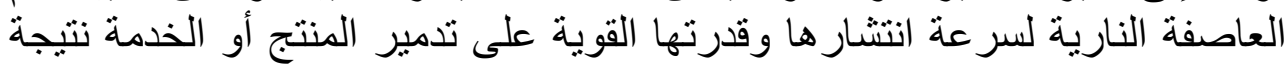

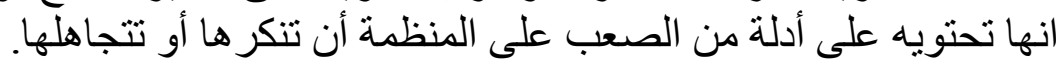

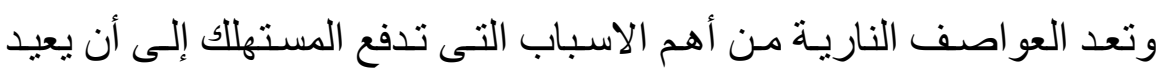

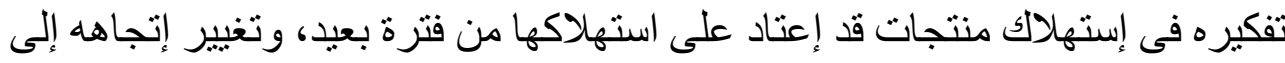

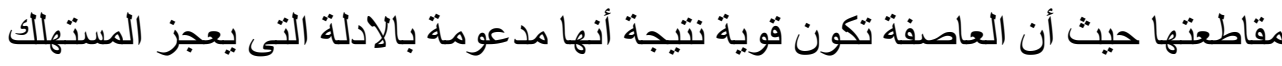

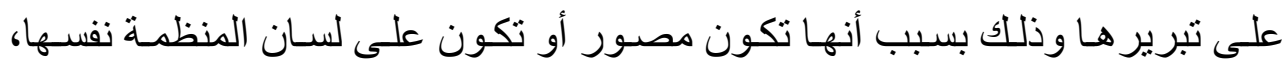

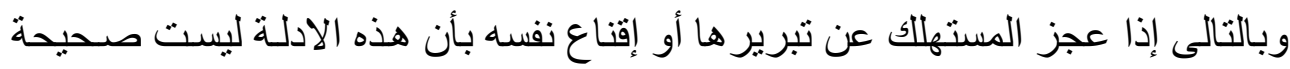
يمكن أن تتحول نو اياه الثر ائية إلى علامة أخرى.

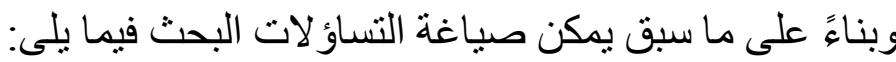

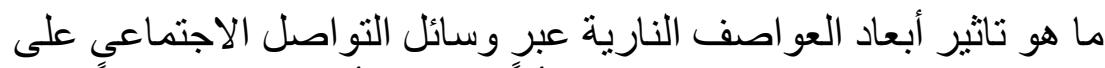

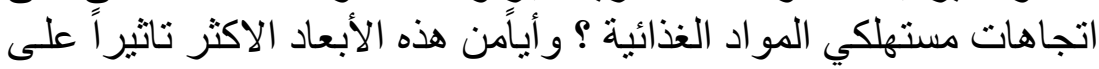

اتجاهات مستهلكي المواد الغذائية ؟

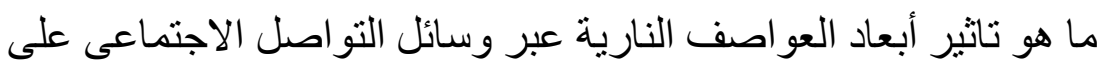
اتجاهات مستهلكي المو اد الغذائية؟ وما نوع هذا ونا التاثير؟

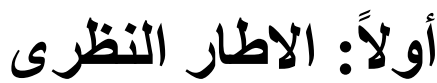

أـ الدراسات السابقة المتعلقة بالعو اصف النارية 
تعد وسائل التو اصل الاجتماعى مـن أهم و اخطر الوسـائل التى للديها

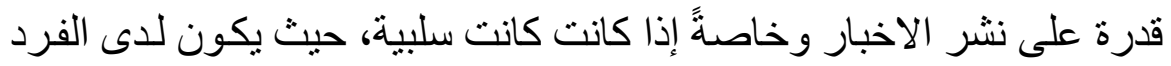

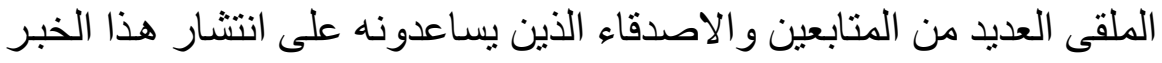

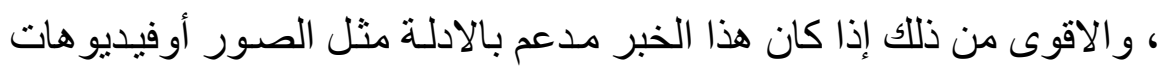

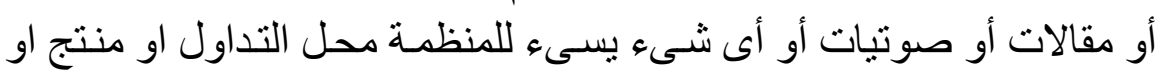

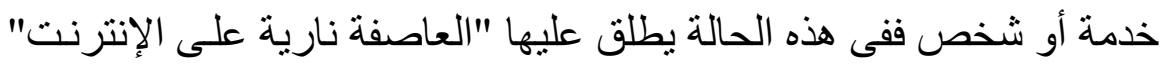
FSO

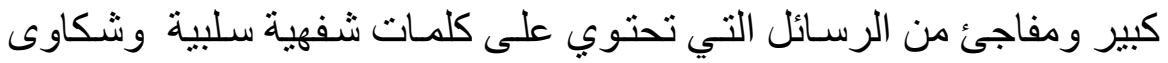

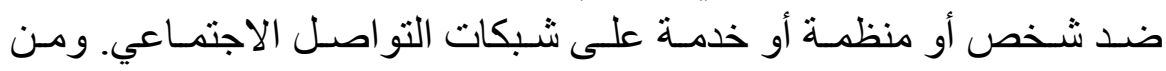

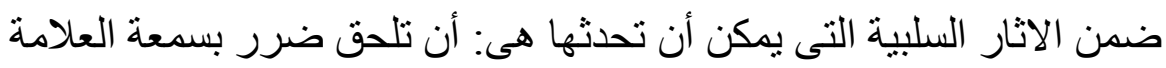

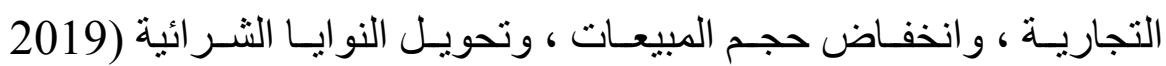

(D’Arco el at.,

ويرى (Pfeffer et al., 2014) أن العاصفة الناريـة هـى موقف

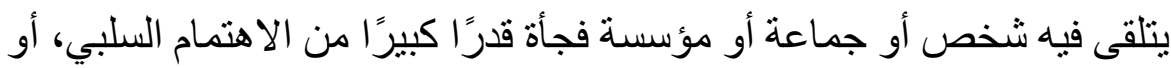

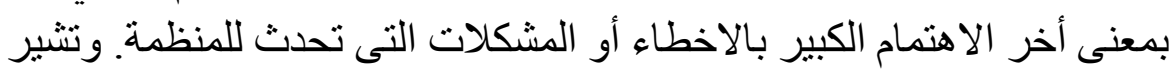

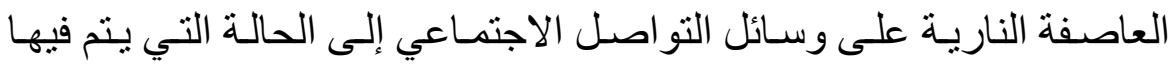

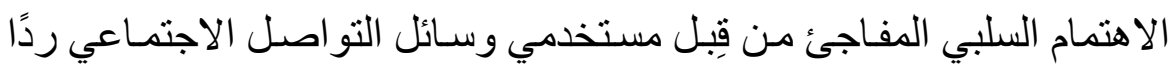

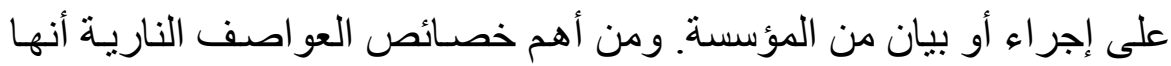

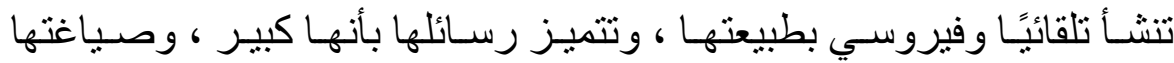
غاضبة ، وتشكيل مناخ من الار اء السبية (Jamba ؛ Johnen et al., 2018

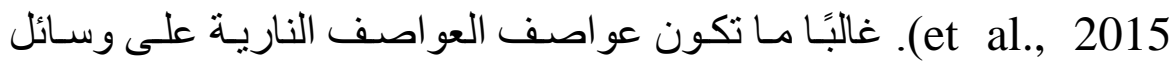

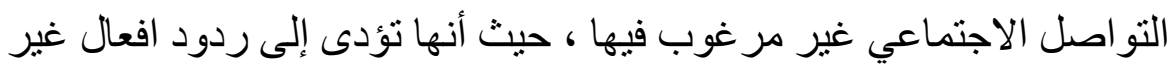

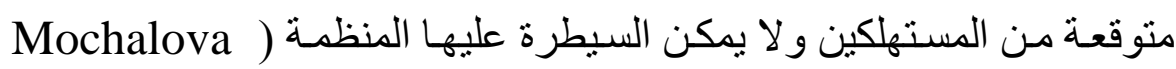
.(and Nanopoulos, 2014

تحـدث العو اصـف الناريـة على مواقـى التو اصـل الاجتمـاعي نظـرًا

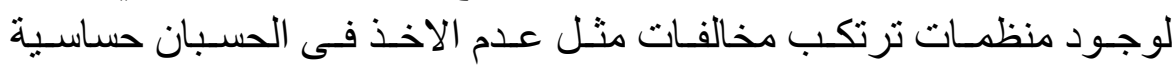

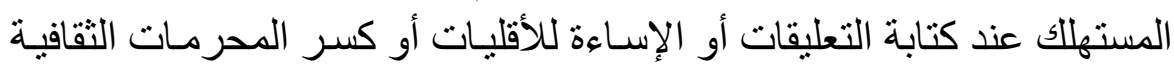

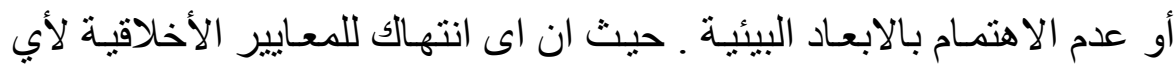

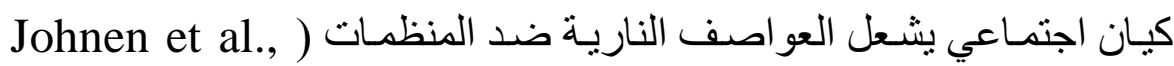

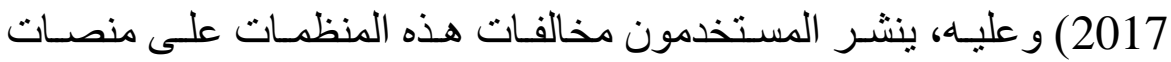


التو اصل الاجتماعي ويتركون رسائل سلبية و عدو انية ضدهم. ومثل هذا النوع التون

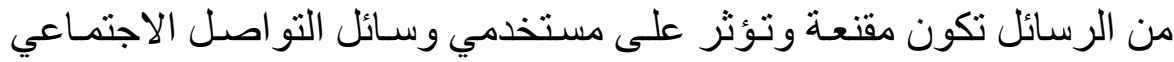

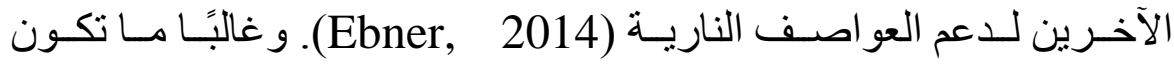

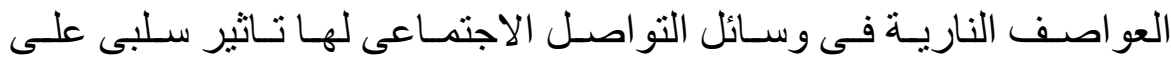

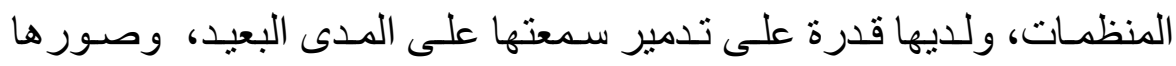

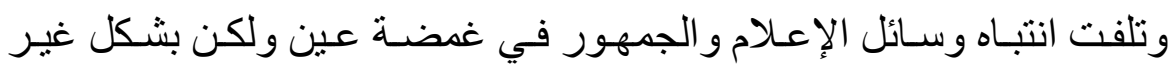

مر غوب فيه (Mochalova and Nanopoulos, 2014)

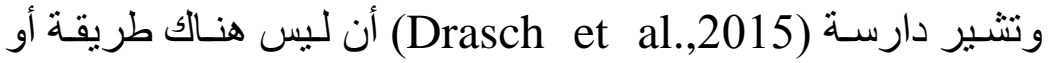

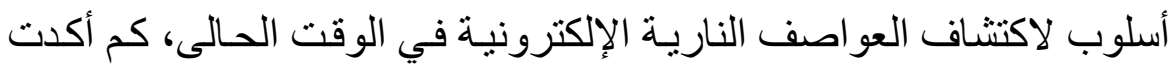

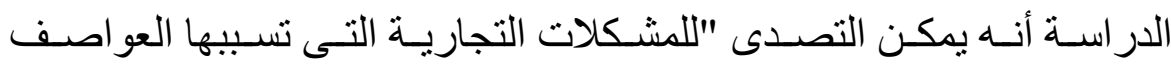

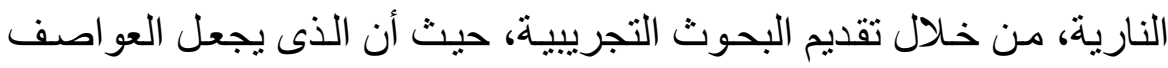

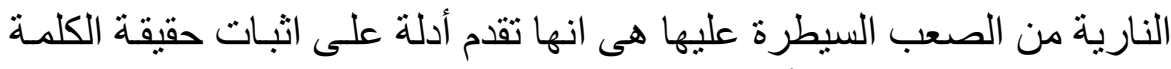

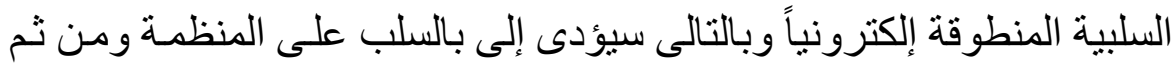

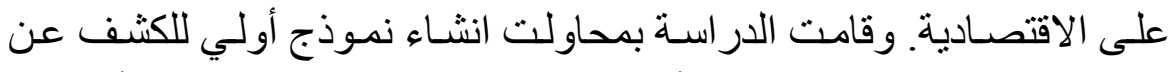

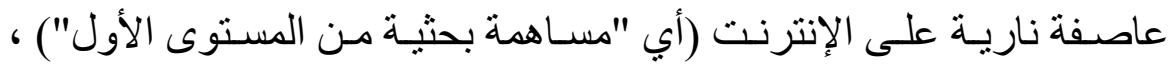

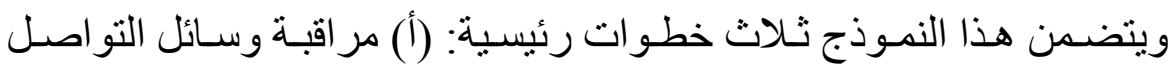

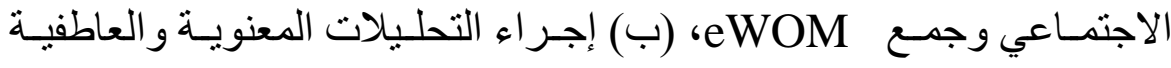

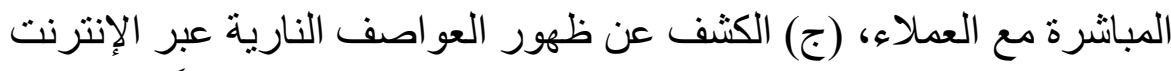

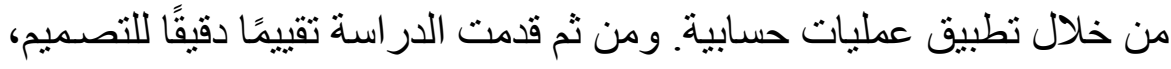

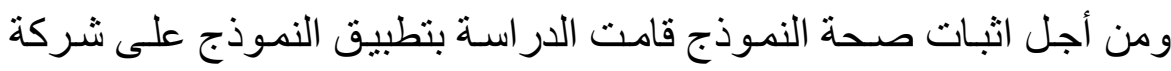

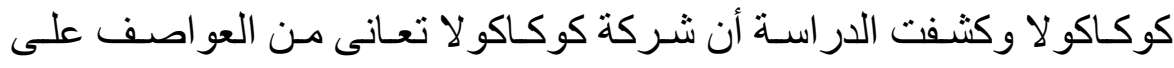

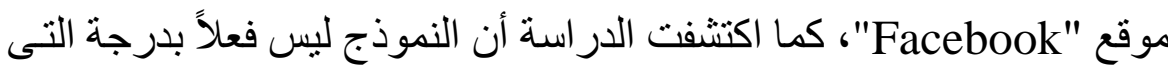
تؤدى للاعتماد عليه فى الدر اسات التى تلحقها.

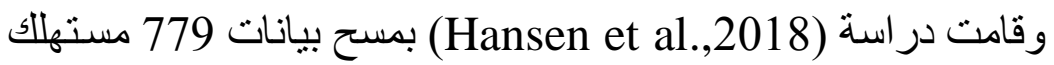

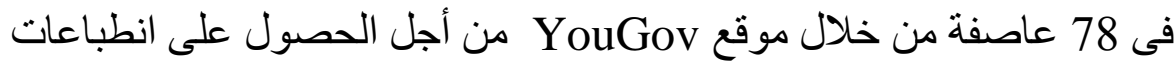

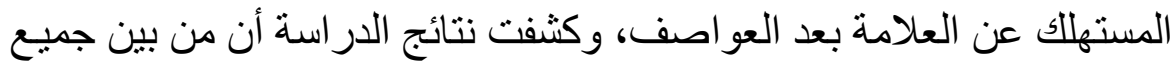

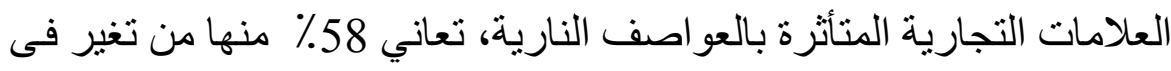

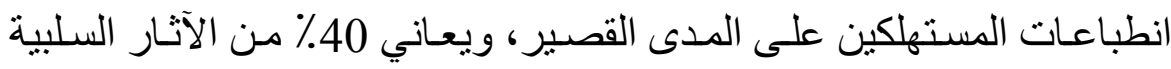

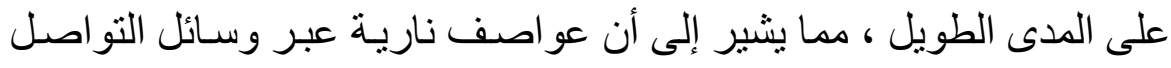

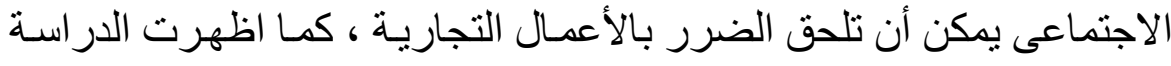

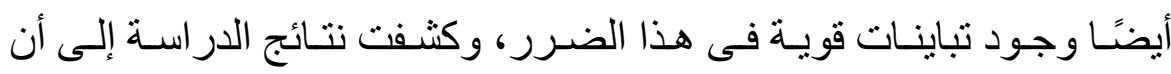




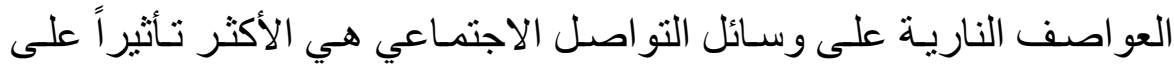

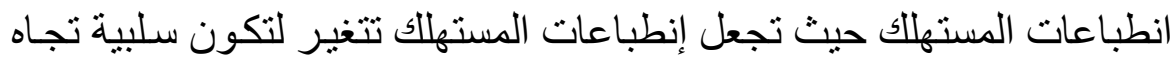

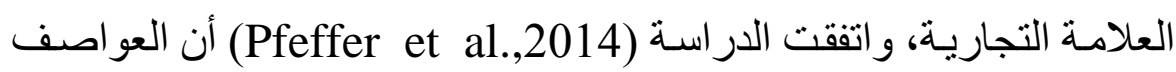

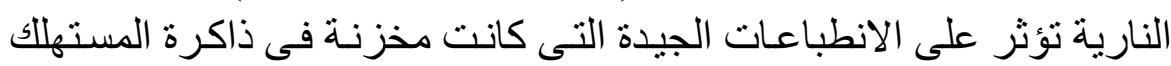

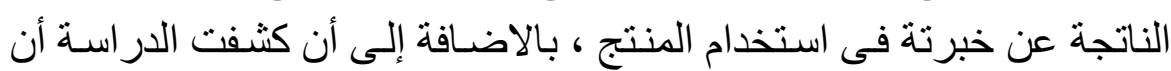

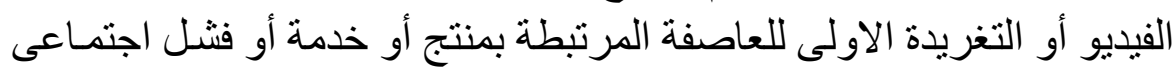
يتم التفاعل معها بشكل كبير ويتم مشاركته فترة الاولى أطول.

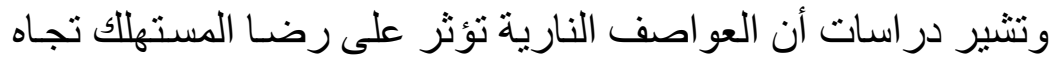

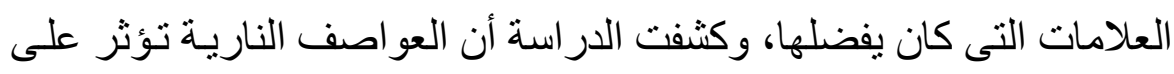

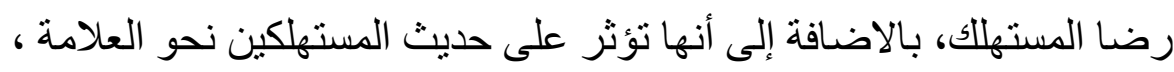

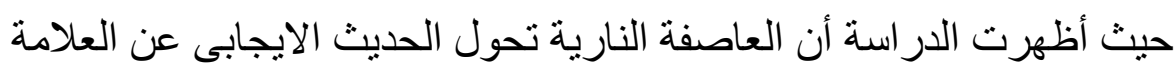

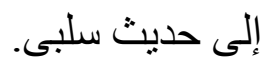

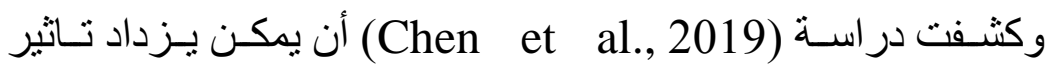

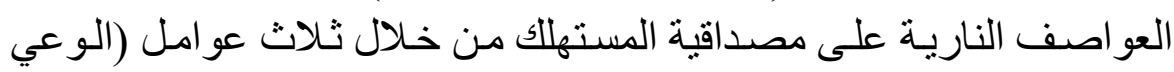

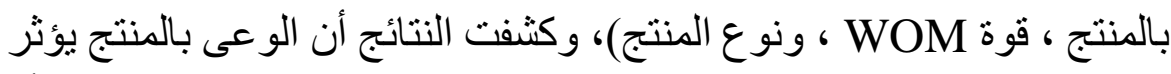

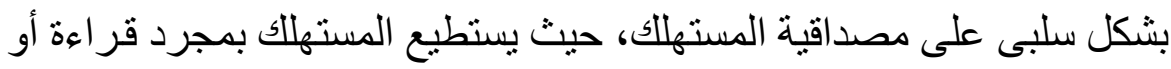

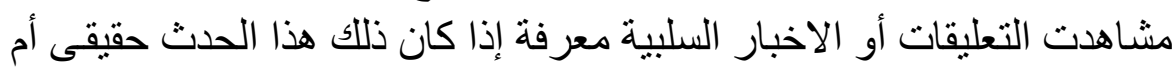

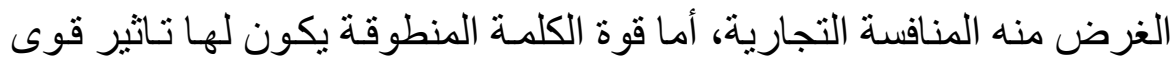

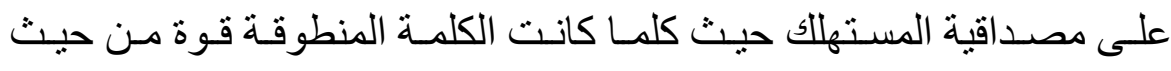

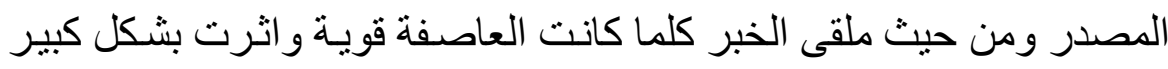

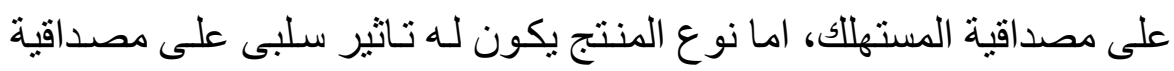

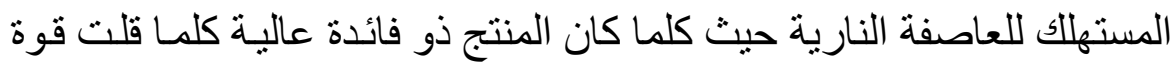

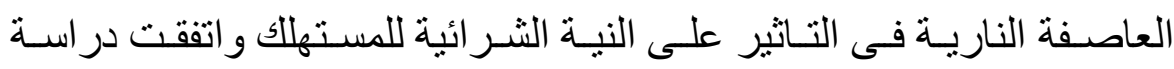

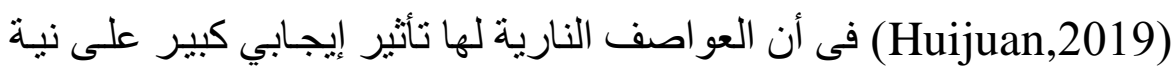

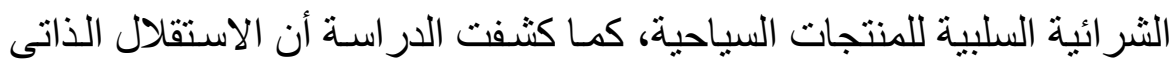

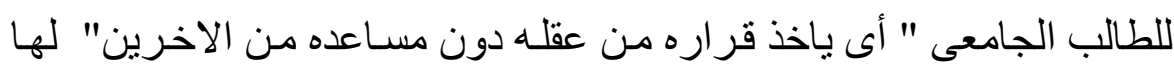

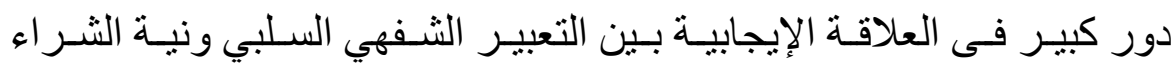

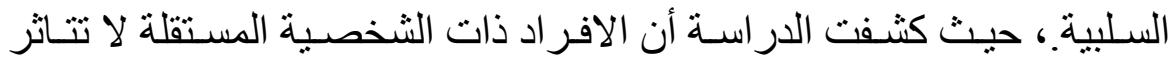

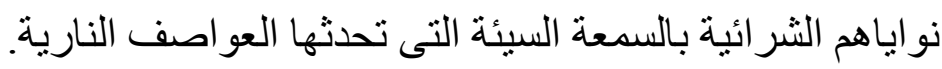

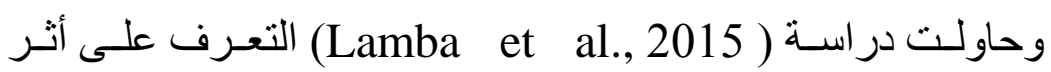
العو اصف النارية على رغبة مستهلك فى عدم الثر اء ومشاركة الحدث و أجل 
اثبات ذلك قامت الدر اسة بعمل تجربـة على عينـة من المستهلكين لمدة خمس اسابيع فاظهرت النتائج فى الثكل التالى:

\begin{tabular}{|c|c|c|c|c|}
\hline القبل عين & العبل ع العبفة & العاصفة & باسبوع بلعة & باسبو عين بعدة \\
\hline & & & & \\
\hline
\end{tabular}

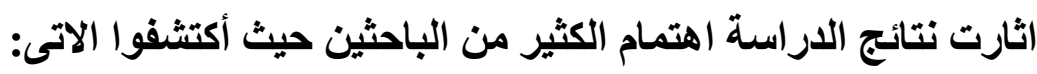

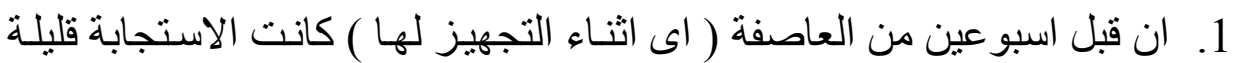

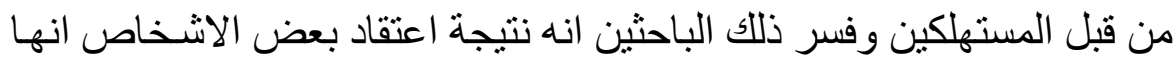
اثناعة ليست لها صحة من الاساس.

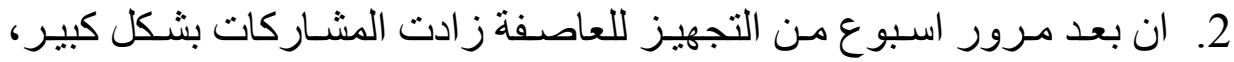

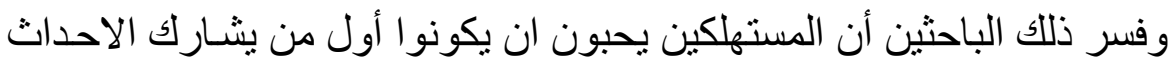

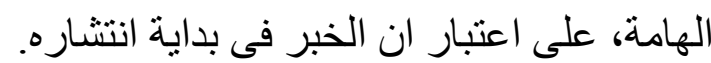

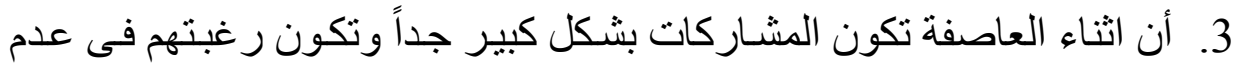
الثر اء مرتفعة جداً، واخذت الثكل التالى:

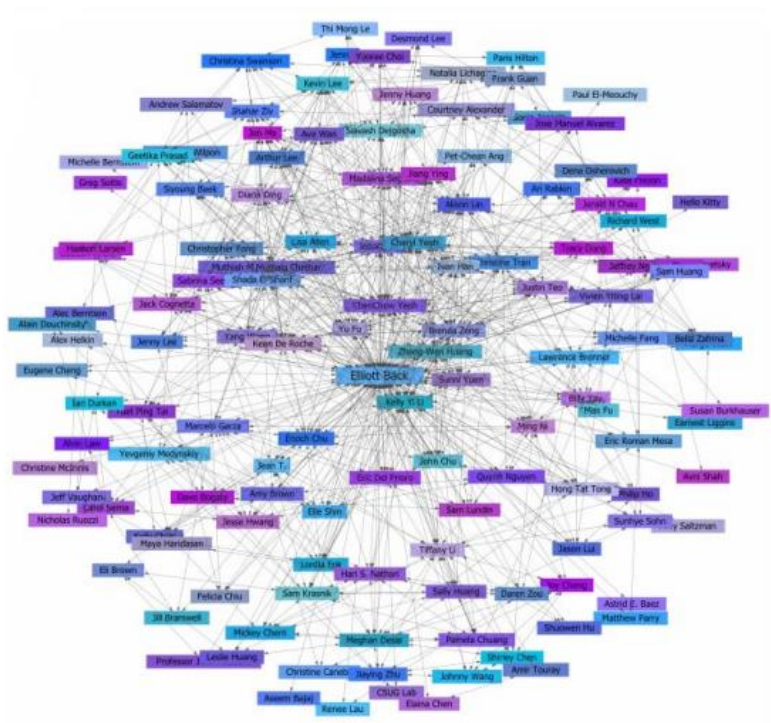

النكل رقم (1) شبكة المشاركات 


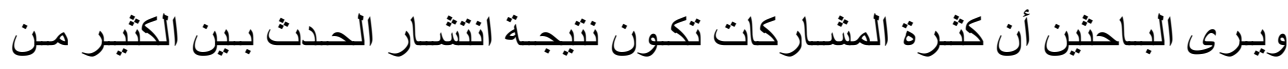

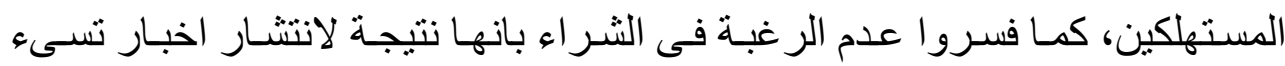

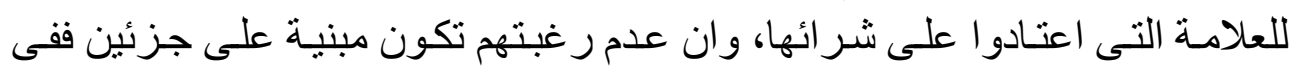

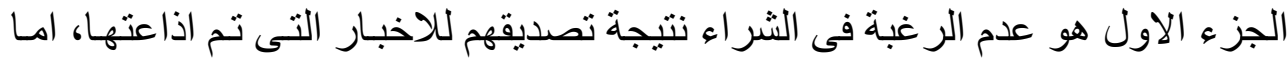

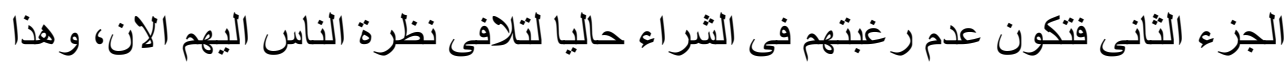
ما فسر نتيجة الاسبو عين بعد العاصفة.

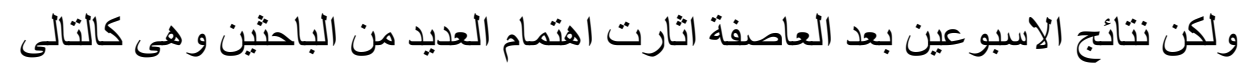

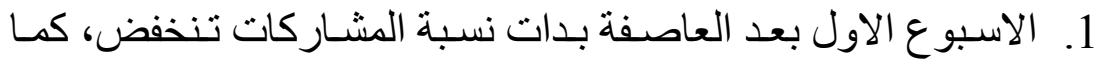

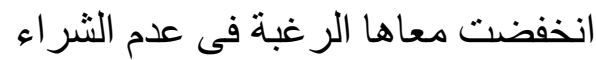

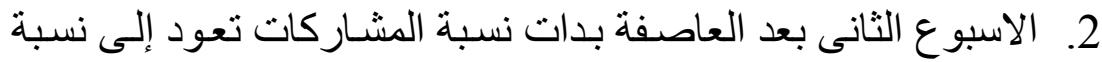
المشاركات قبل بدء العاصفة باسبو عين.

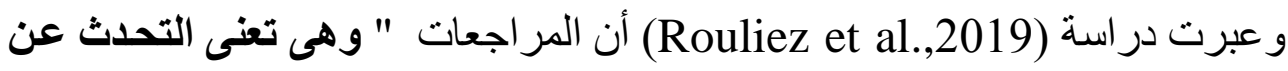

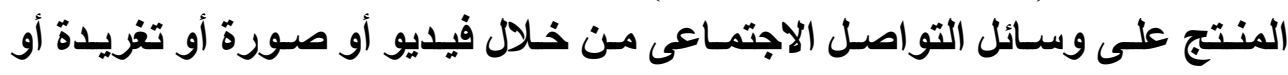

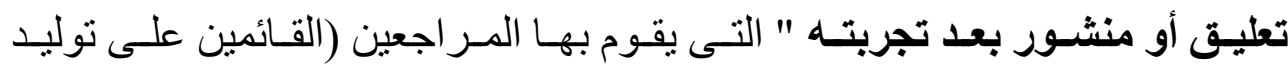

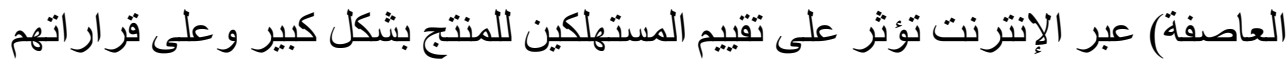

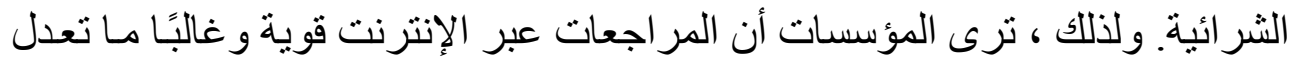

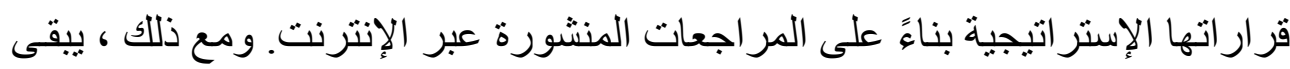

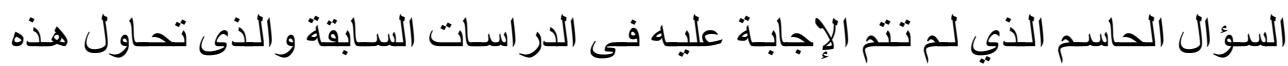

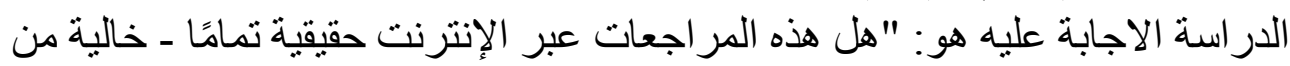

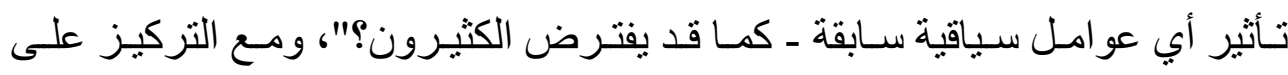

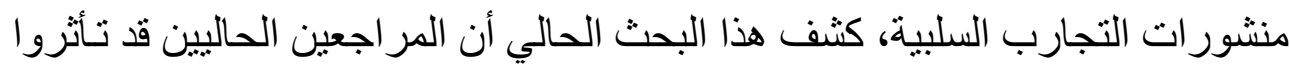

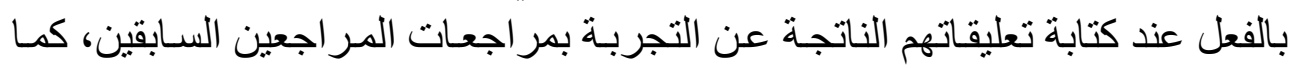

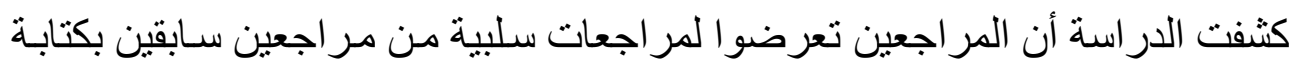

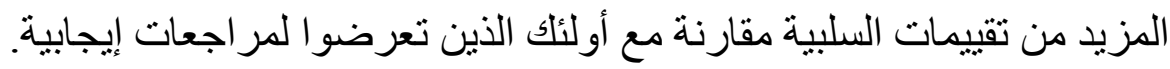

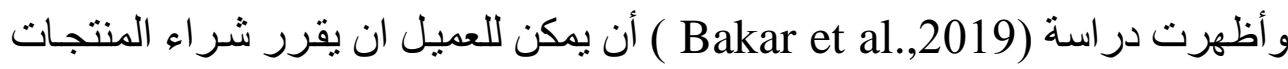

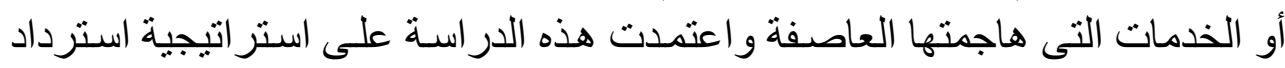

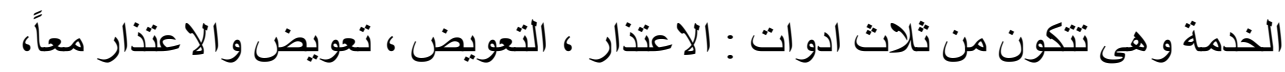

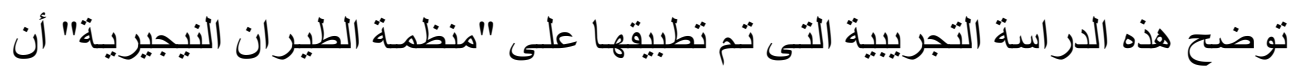

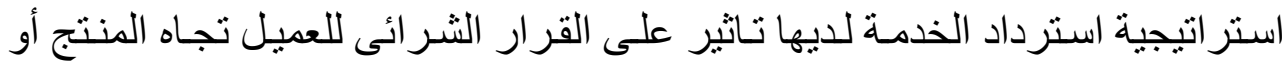

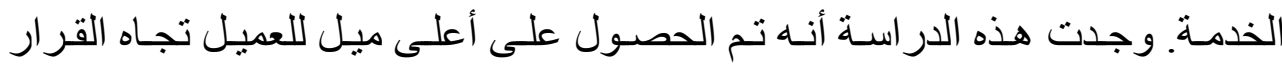

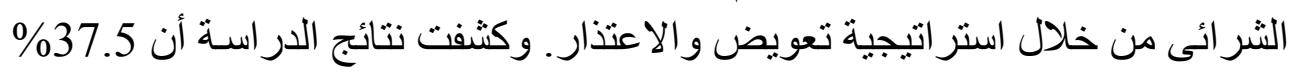




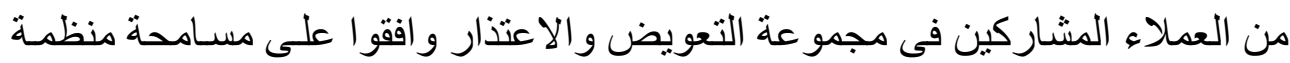

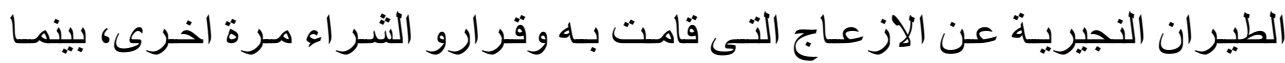

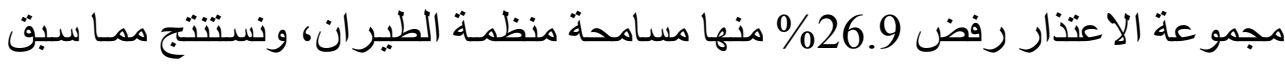

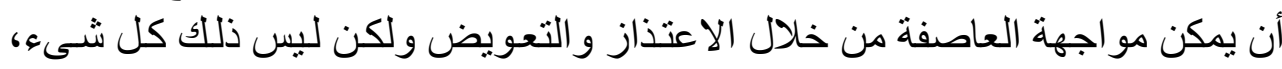

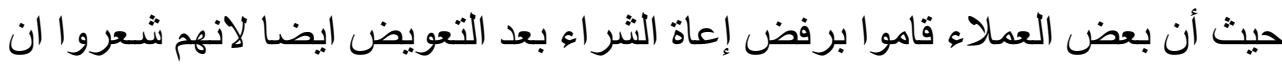

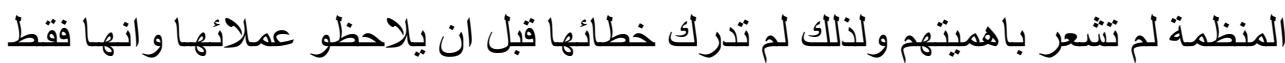

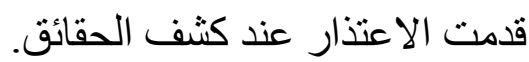

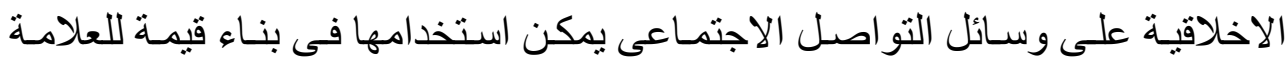

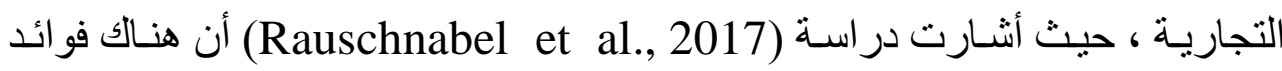

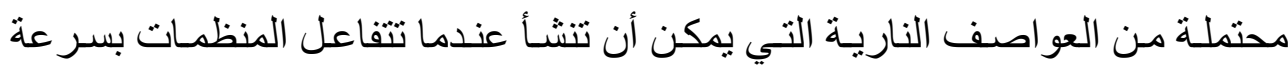

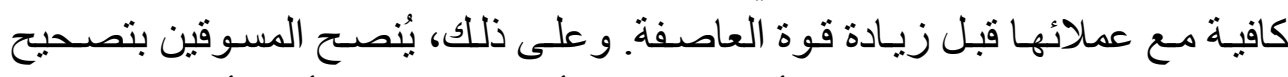

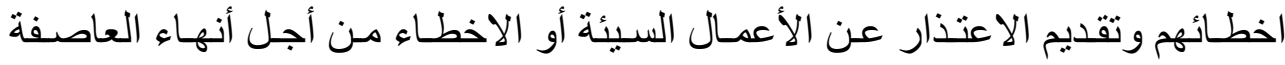

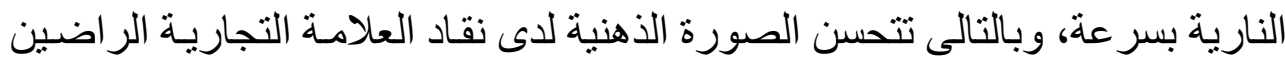

.(Pfeffer et al., 2014 ؛ Salle \& Grégoire, 2015) وسوف يتناول البحث عدة أبعاد في متغير العو اصف الناريـة عبر وسـائل التو اصل لـ

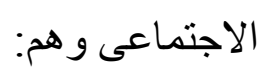

مhe power of information ) قوة المعلومـات المشـاركة في الخبر (involved in the news

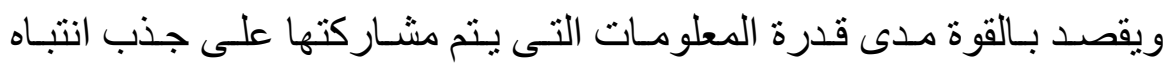
العملاء وجعلهم يشاركونها مع الاخرين.

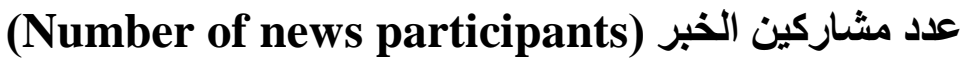

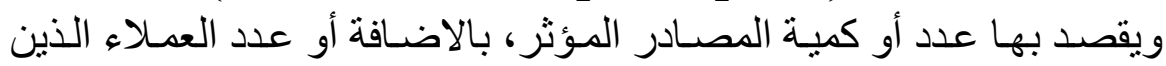

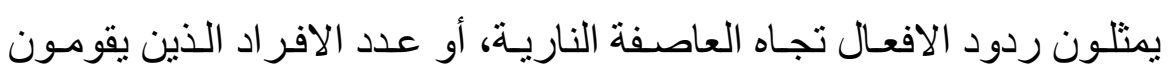
بمشاركة الاخبار التى تخص العاصنة تجاه العاصفة

الفورية فى نشر الخبر (Immediate publication of the news)

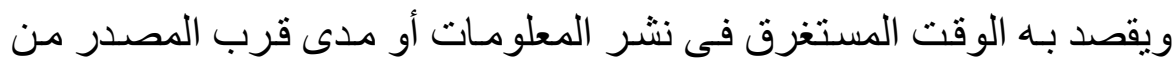

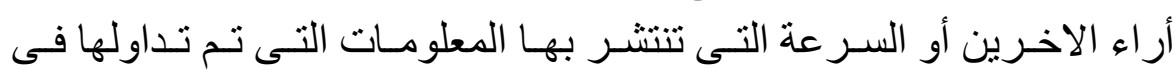


ب- الدراسات السابقة الخاصة باتجاهات المستهلك التكات

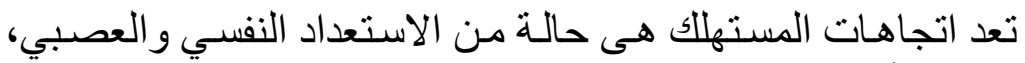

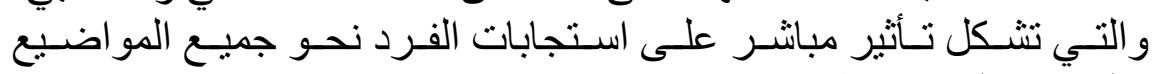
و الحالات التي ترتبط بها (Chawla\& Joshi, 2019)

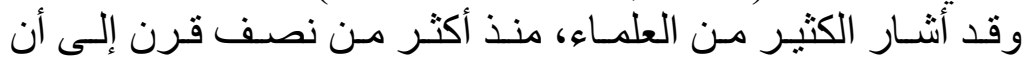

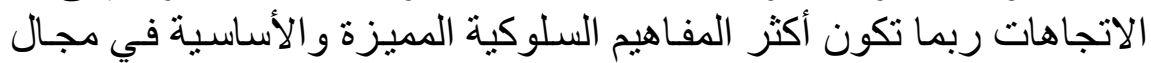

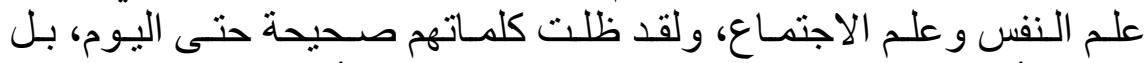

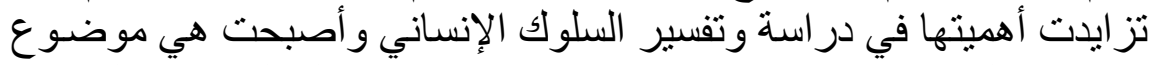

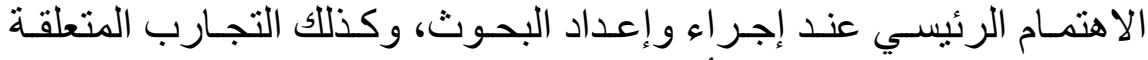

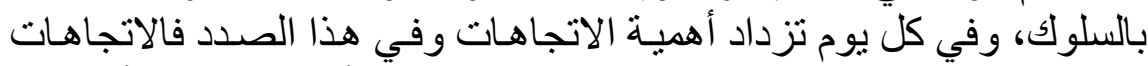

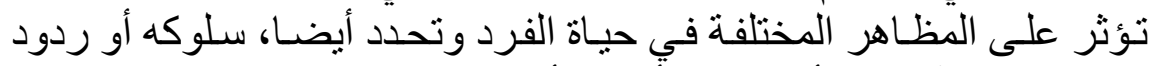

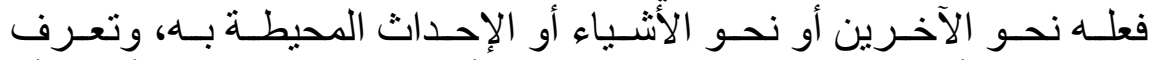

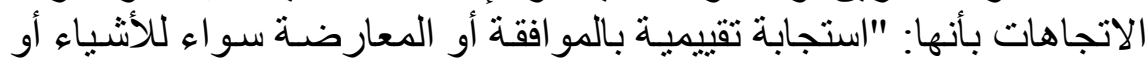

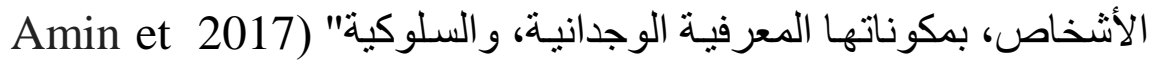

كام قام الباحثين بالعديد من الدراسات التى تربط بين متغير اتجاهات

(al.,

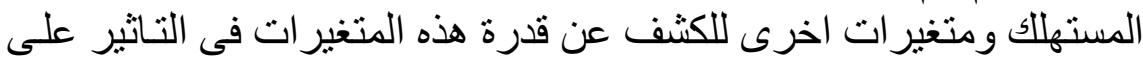

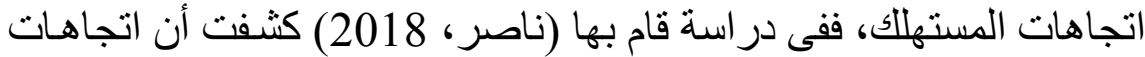

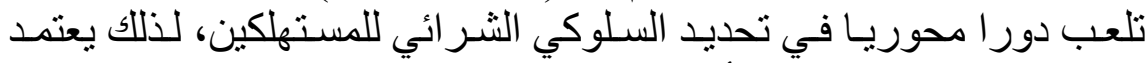

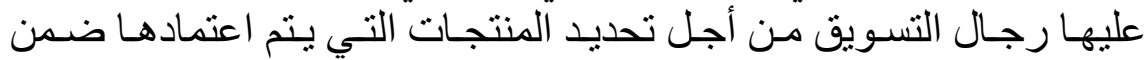

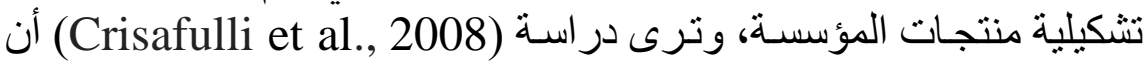

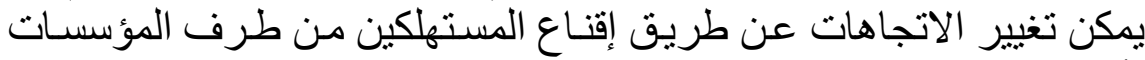

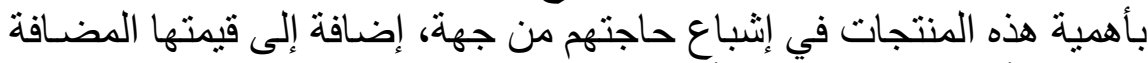

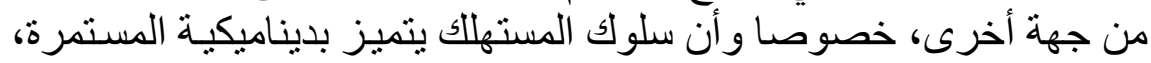
نتيجة لتغير معارفه وتأثير تجارية.

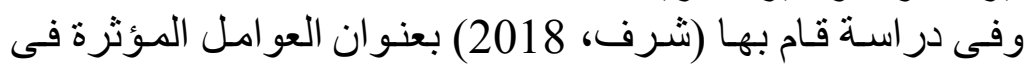

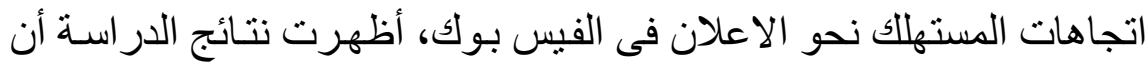

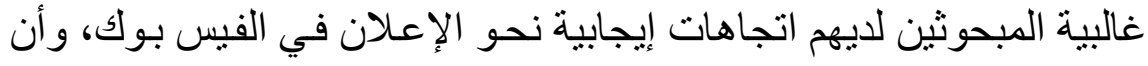

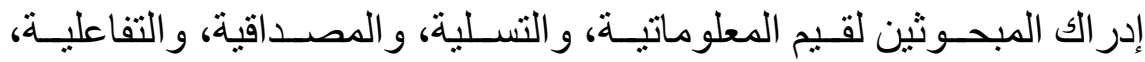

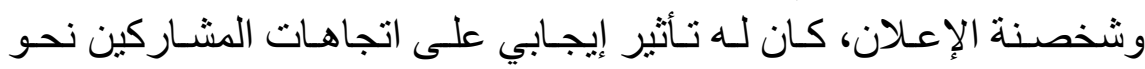

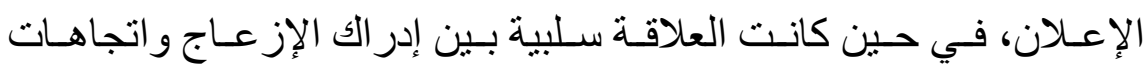

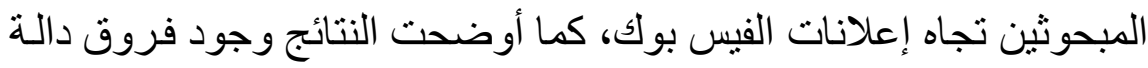
إحصائية في اتجاهات المستهلكين نحو إعلانات الفيس بوك تبعان الناف لاختلاف 
متغير النـوع، كمـــ كثـفت دراسـة (شـلبى، 2018) أن اتجاهـات السـلوكية للعميل تؤثر على النية الثر ائية للعميل.

وقامت در اسـة (Crisafulli et al., 2008) بتحديد العلاقة بين

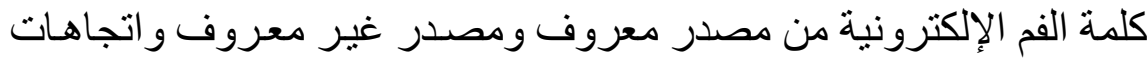

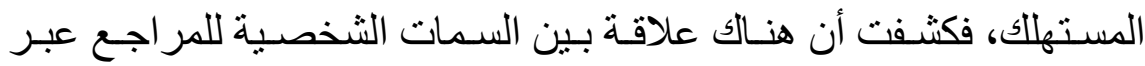

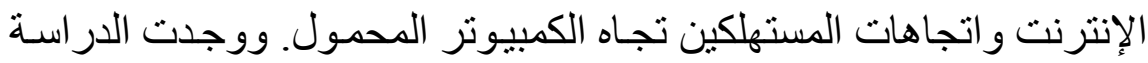

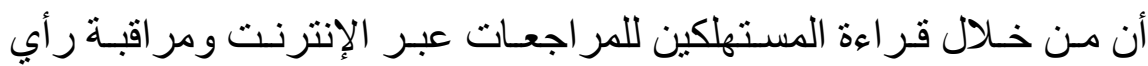

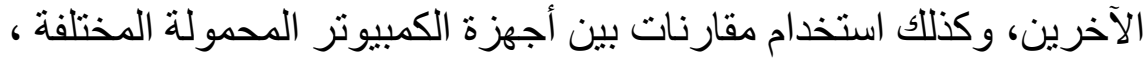

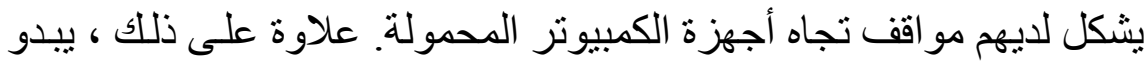

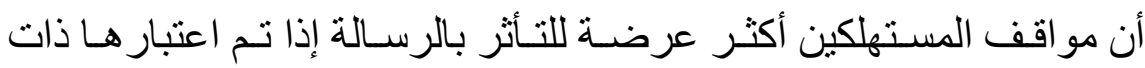

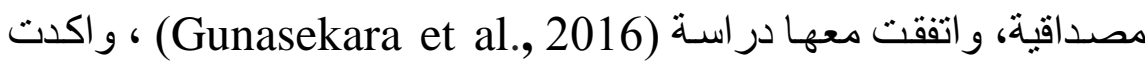

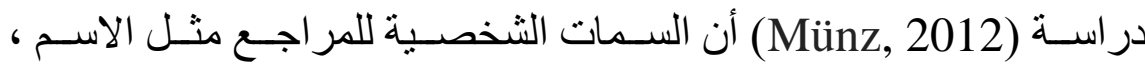

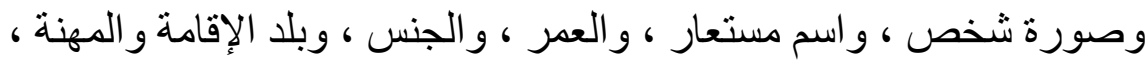

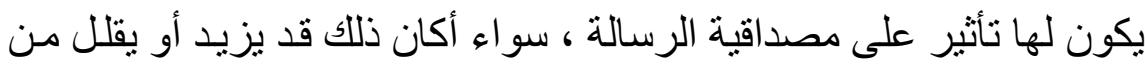

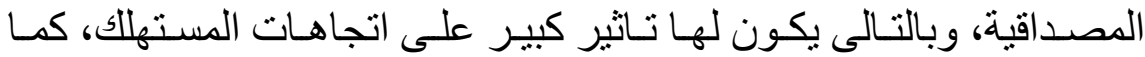

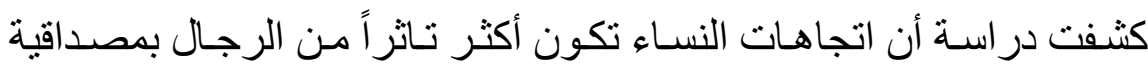

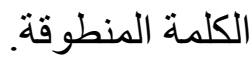

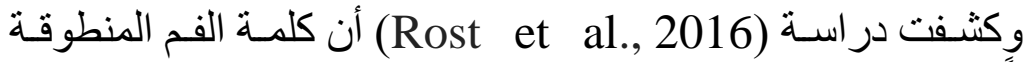

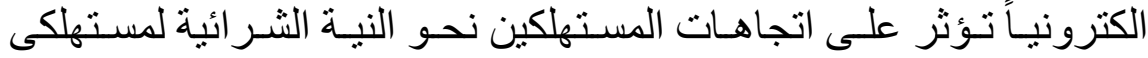

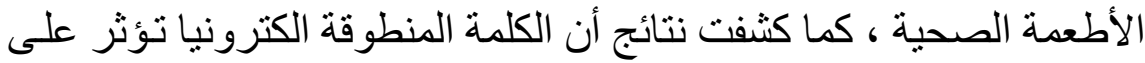

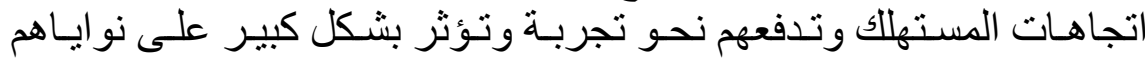

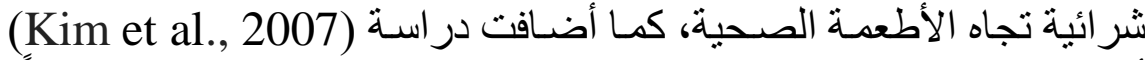

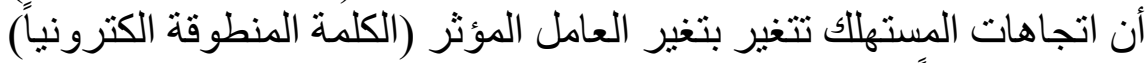

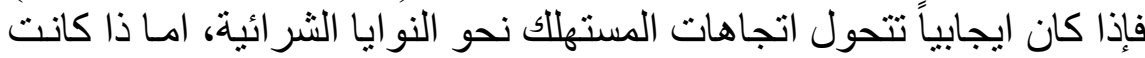

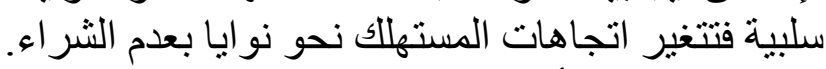
وسوف يتناول البحث عدة أبعاد فى هذا المتغير و هم: المئري

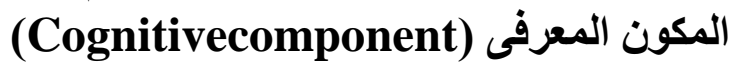

يعتبر المكون الاول للاتجاهـات ويتكون من مدركات الاشتخاص مـع امكانيـة التفاعل المباشر مع الثىى الألى يبنى عليه الاتجاه (صديق، 2014)

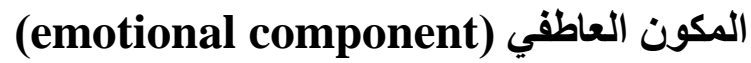

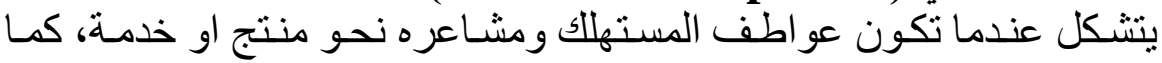

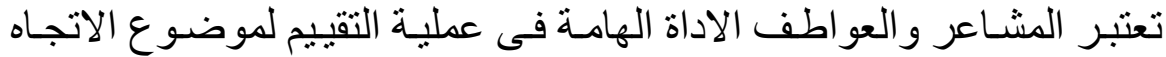
(schiffman, 2014) 
• المكون السلوكى (Behavioral component)

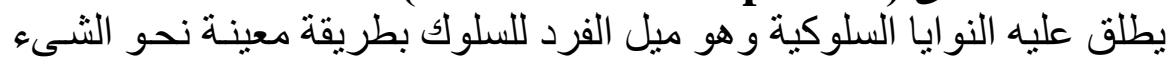

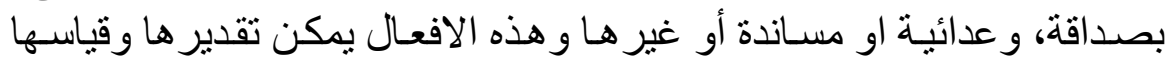

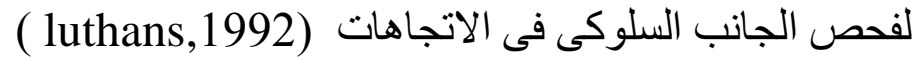
بناءً على ما تم الاشارة إليه من الدراسات السابقة يمكن صياغة فروض البحث فيما

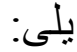

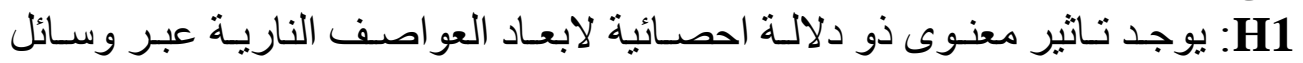
التو اصل الاجتماعى على اتجاهات مستهلكي المواد الغذائية. وينبثق عن هذه الفرضية الرئيسية الفروض الجاتئ الفرعية الاتية:

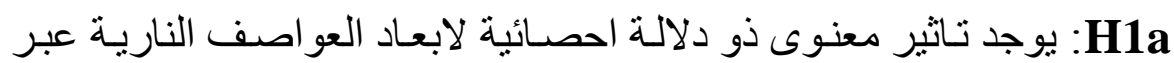

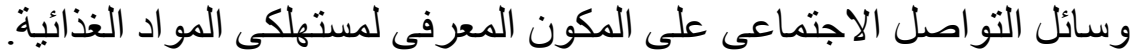

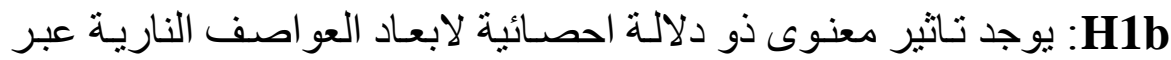
وسائل التو اصل الاجتماعى على المكون العاطفى لمستهلكي المو اد الغذائية. وباتئ :H1c وسائل التو اصل الاجتماعى على المكون السلوكى لمستهلكي المواد الغذائية.

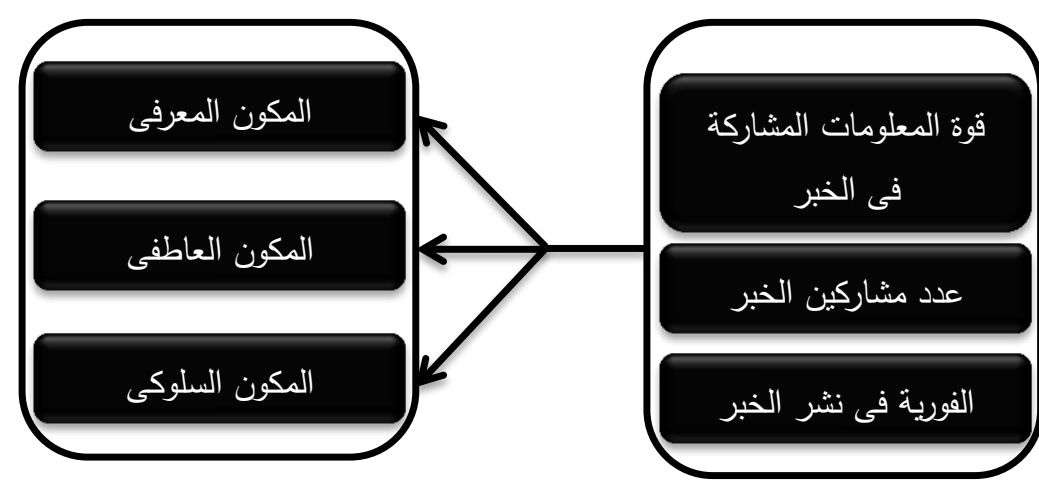

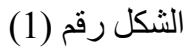

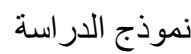

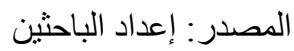

اعتمد الباحثين فى هذه الدر اسة على:

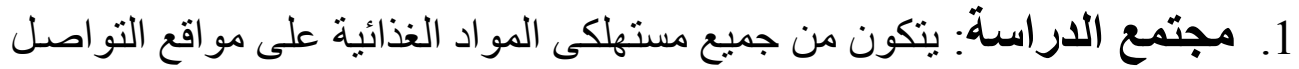

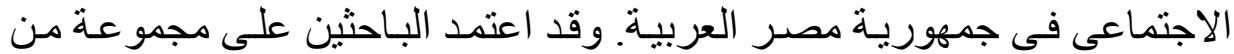

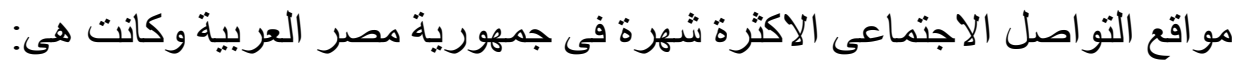

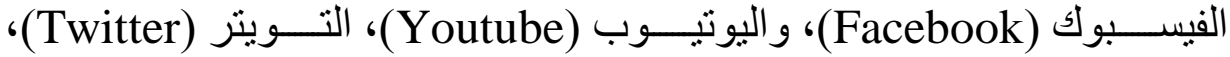


والانستاغر ام (Instagram)، بالاضـافة إلى تـرك اختيـار مفتوح للعمـلاء التىى

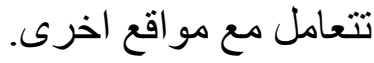

2. عينة الاراسة : اعتمد الباحثين على على أخذ إعتر اضية منتظمة عبر الانترنت

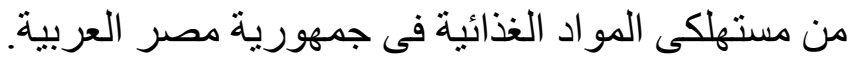

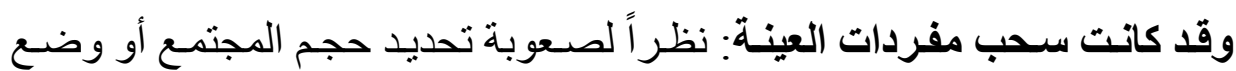

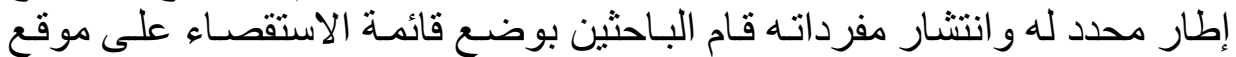

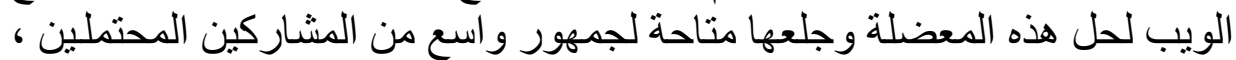

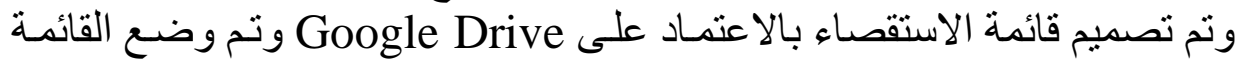

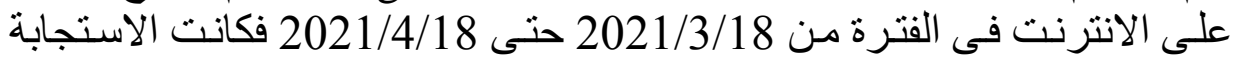

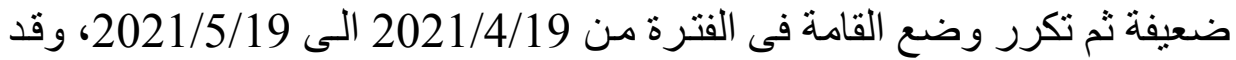

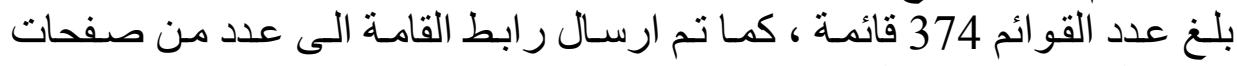

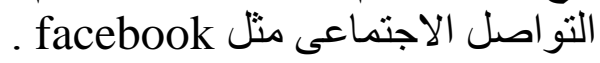

\section{> حجم العينة: بلغ حجم الاستجابة 374 مفردة.

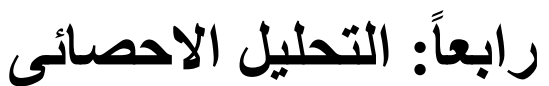

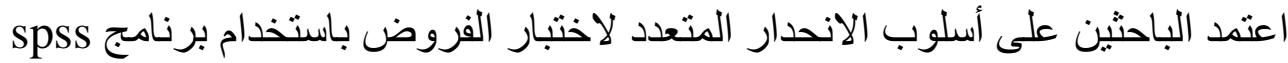

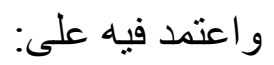

\section{أـ ت تقييم نموذج وليه القياس:}

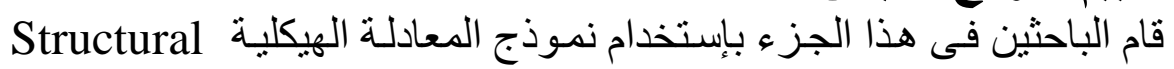

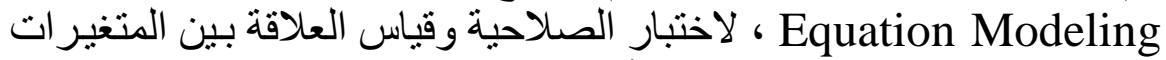

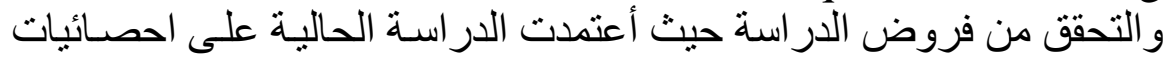

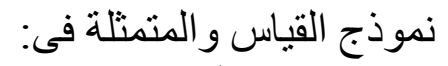

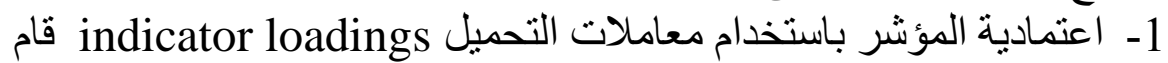
الباحثين بتقييم الثبات للعبار ات باستخدام التحميلات المجئل التمعة و التحميلات المتقطعة combined loadings and cross loadings وهذه باله التحميلات كونت structure-matrix （un-rotated و التى تحتوى وهن على معامل ارتباط بيرسون بين عبار ات القياس و المتغير ات الكامنـة،

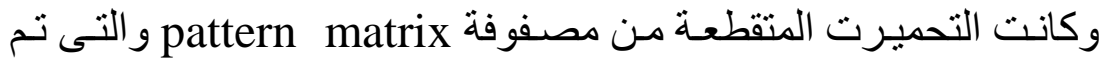

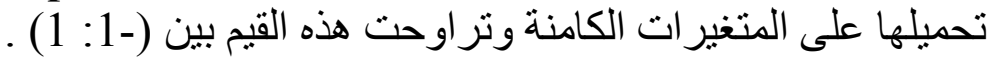

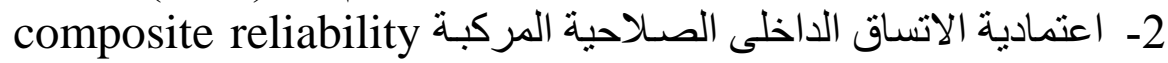

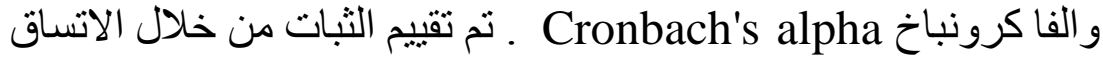

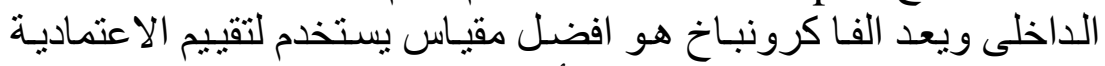

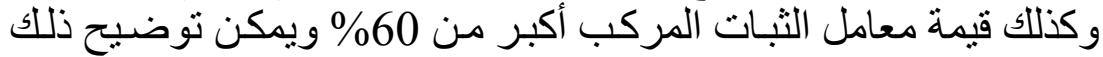

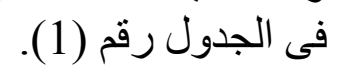


3- الصلاحية التقاربية convergent validity عن طريق حساب منوسط :

3 التباين المستخرج Average variance extracted : تم قياس متوسط

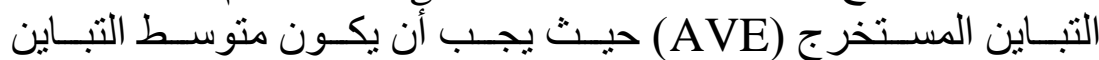

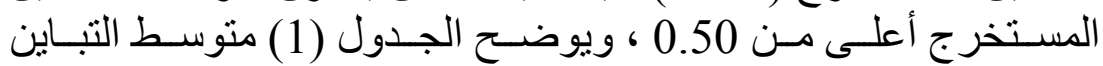

المستخرج حيث يوضح أنه كانت نسبة متوسط التباين أعلى من 0.50

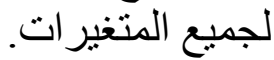

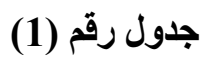

معامل ثبات الاتساق الداخلى لابعاد الاستمار (كرونباخ الفا)

\begin{tabular}{|c|c|c|c|c|c|c|c|}
\hline المبات & المتتباين & الصدق & كرونباخ & الالعيارى & المتوسط & الرمز & المتغير \\
\hline \multirow{4}{*}{0.790} & \multirow{4}{*}{0.983} & \multirow{4}{*}{0.677} & \multirow{4}{*}{0.938} & 1.236 & 4.22 & a1 & \multirow{4}{*}{ المشلومات الخبرة } \\
\hline & & & & 1.264 & 4.17 & $\mathrm{a} 2$ & \\
\hline & & & & 1.233 & 4.21 & a3 & \\
\hline & & & & 1.238 & 4.19 & a4 & \\
\hline \multirow{5}{*}{0.646} & \multirow{5}{*}{0.916} & \multirow{5}{*}{0.657} & \multirow{5}{*}{0.896} & 1.33024 & 3.9492 & b1 & \multirow{5}{*}{ مشاركين } \\
\hline & & & & 1.32865 & 3.9358 & b2 & \\
\hline & & & & 1.31234 & 3.9599 & b3 & \\
\hline & & & & 1.30668 & 3.9813 & b4 & \\
\hline & & & & 1.37183 & 3.7995 & b5 & \\
\hline \multirow{4}{*}{0.616} & \multirow{4}{*}{0.864} & \multirow{4}{*}{0.66} & \multirow{4}{*}{0.862} & 1.47477 & 3.6952 & w1 & \multirow{4}{*}{ تشرو الخبة فى } \\
\hline & & & & 1.40887 & 3.7487 & w2 & \\
\hline & & & & 1.43908 & 3.7005 & w3 & \\
\hline & & & & 1.46532 & 3.6684 & w4 & \\
\hline \multirow{8}{*}{0.507} & \multirow{8}{*}{0.892} & \multirow{8}{*}{0.62} & \multirow{8}{*}{0.891} & 1.46363 & 3.4652 & $\mathrm{q} 1$ & \multirow{8}{*}{ المعرفى } \\
\hline & & & & 1.467 & 3.5455 & $q^{2}$ & \\
\hline & & & & 1.50808 & 3.4438 & $\mathrm{q} 3$ & \\
\hline & & & & 1.43409 & 3.5321 & $\mathrm{q} 4$ & \\
\hline & & & & 1.43895 & 3.4439 & q5 & \\
\hline & & & & 1.46221 & 3.5 & q6 & \\
\hline & & & & 1.39613 & 3.5348 & q7 & \\
\hline & & & & 1.48754 & 3.4813 & q8 & \\
\hline \multirow{5}{*}{0.681} & \multirow{5}{*}{0.914} & \multirow{5}{*}{0.681} & \multirow{5}{*}{0.913} & 1.36831 & 3.8235 & p1 & \multirow{5}{*}{ العاطفى } \\
\hline & & & & 1.44597 & 3.7513 & $\mathrm{p} 2$ & \\
\hline & & & & 1.3403 & 3.885 & p3 & \\
\hline & & & & 1.36438 & 3.8235 & $\mathrm{p} 4$ & \\
\hline & & & & 1.44397 & 3.7299 & p5 & \\
\hline \multirow{5}{*}{0.631} & \multirow{5}{*}{0.895} & \multirow{5}{*}{0.697} & \multirow{5}{*}{0.895} & 1.45051 & 3.6123 & $\mathrm{t} 1$ & \\
\hline & & & & 1.4461 & 3.6898 & $\mathrm{t} 2$ & \\
\hline & & & & 1.48599 & 3.7059 & t3 & المكون \\
\hline & & & & 1.47715 & 3.7513 & $\mathrm{t} 4$ & \\
\hline & & & & 1.50066 & 3.6417 & t5 & \\
\hline
\end{tabular}




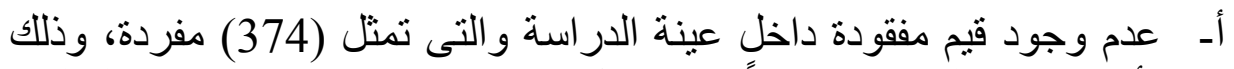

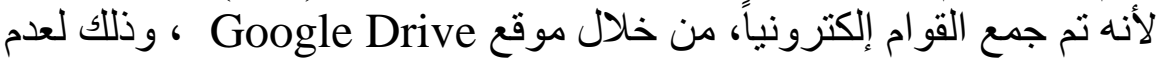
إمكانية تخطى أحد الأسئلة دون إجابة علية عليه وذللك من ضمن الاختيارات المتاحة عند تصميم القائمة.

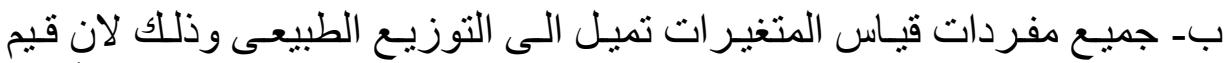

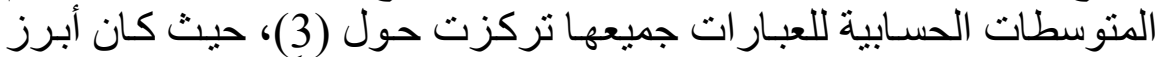

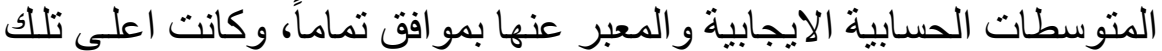

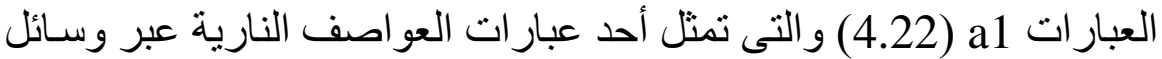

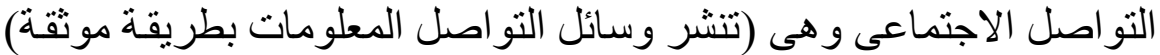

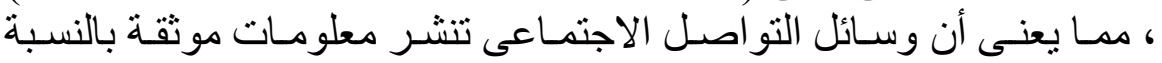

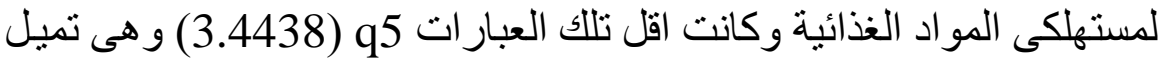

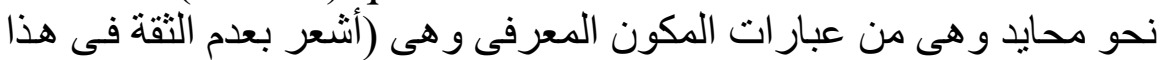

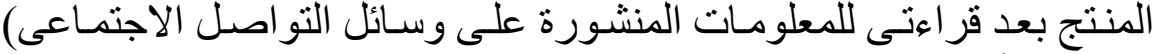

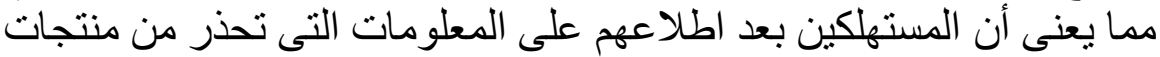
معينة على وسائل التو اصل الاجنماعى اصبحو غير الطير واثقين فى هذه المنتجات

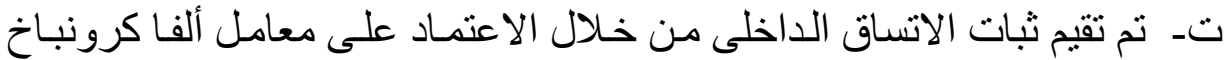

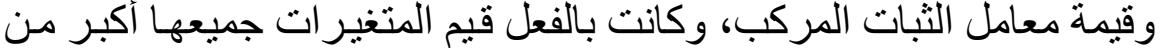

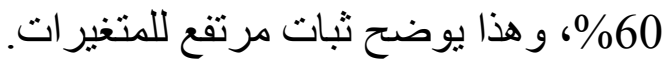

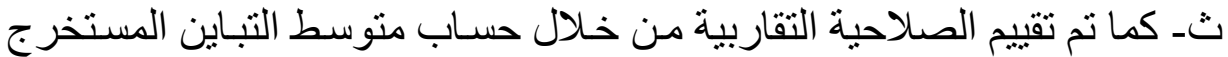

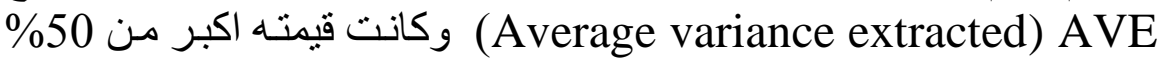

$$
\text { لجميع المتغيرات. }
$$

3isciminant validity الصلاحية التمييزية الجنية

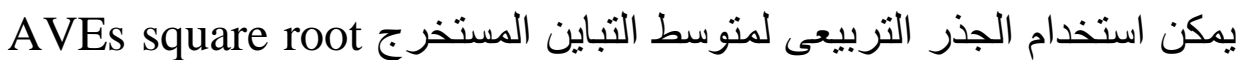

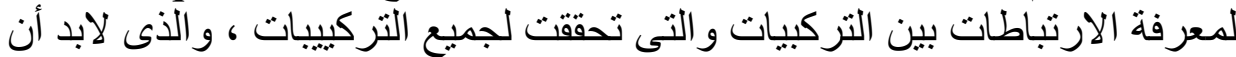

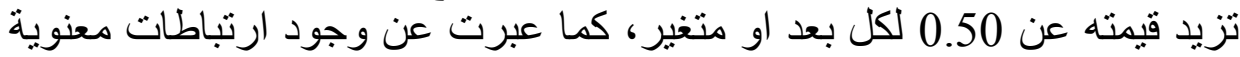
بين تلاك المتغير ات من خلال مصفوفة الارتباط. 


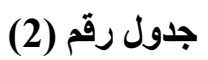

Square roots of AVEs مصفوفة الارتباط والجدر التربيعى لمتوسط التباين المستخرج

\begin{tabular}{|c|c|c|c|c|c|c|}
\hline السلوكى & العاطفىن & المعرفى & في نشرية & مشاركين & قوة المعلومة فيات & \\
\hline 0.091 & 0.194 & 0.166 & 0.158 & 0.245 & $(0.8895)$ & المشاركة \\
\hline 0.267 & 0.274 & 0.133 & 0.127 & $(\mathbf{0 . 8 0 3 2})$ & 0.245 & مشاركين \\
\hline 0.18 & 0.109 & 0.07 & $(0.7845)$ & 0.127 & 0.158 & في نشرية \\
\hline 0.168 & 0.162 & $(0.8429)$ & 0.07 & 0.133 & 0.166 & المعرفى المكى \\
\hline 0.223 & $(0.8474)$ & 0.162 & 0.109 & 0.274 & 0.194 & العاطفىن \\
\hline$(\mathbf{0 . 8 0 3 8})$ & 0.223 & 0.168 & 0.18 & 0.267 & 0.091 & السلوكىن \\
\hline
\end{tabular}

المصدر: نتائج التحليل الاحصائى برنامج Spss 23 وAmos 23 ملحوظة (P) (P)

بـ النموذج الهيكلى: تتضمن الخطوة التالية لتقييم النموذج الهيكلى التهيك تقييم

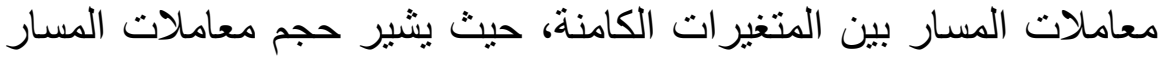

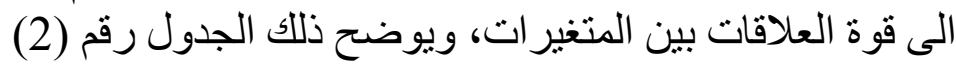

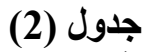

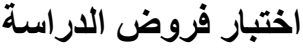

\begin{tabular}{|c|c|c|c|c|c|c|c|}
\hline النتائج & المعنوية & التاثير & معاملات & التابعي & الوسنيطي & المستضيل & الفروض \\
\hline الفرضول & 0.003 & 0.024 & . 156 & & المعرفى & الالنارية عبر & H1a \\
\hline الفرضول & 0.000 & 0.062 & 0.250 & & العاطفى & الأنارية عبر التواصل & H1b \\
\hline الفرض & 0.000 & 0.055 & 0.234 & & السلوكى & النارية التوائل عبر & H1c \\
\hline
\end{tabular}

المصدر: نتائج التحليل الاحصائى برنامج 23 Spss وAmos 23 


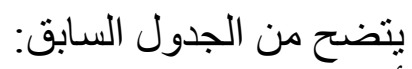

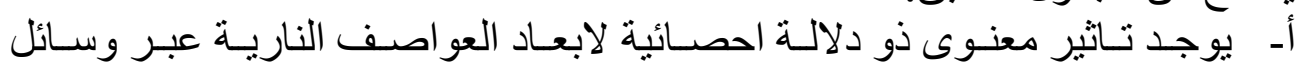

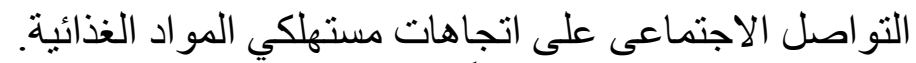

تم قبول الفرض الرئيسى كلياً

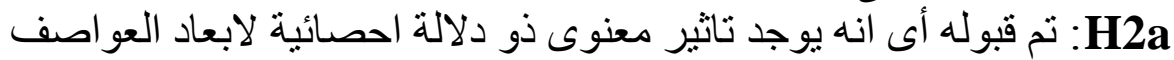

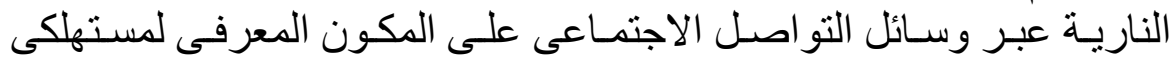

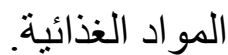

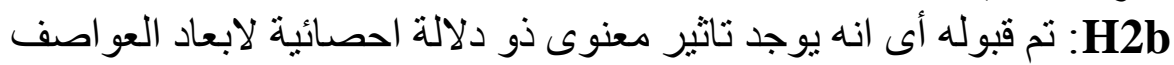

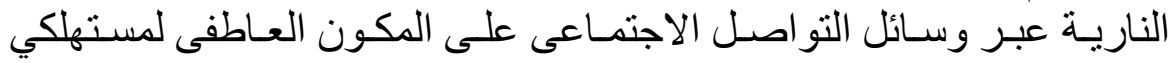

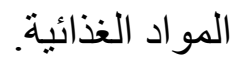

:H2c

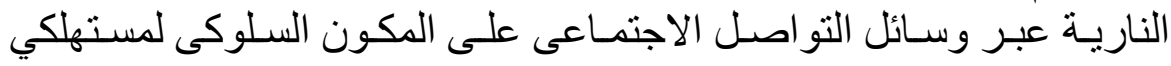

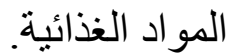

\section{خامساً: مناقشة التشة التتائج والتوصيات}

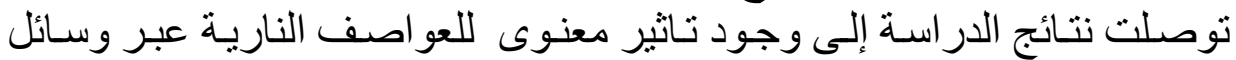

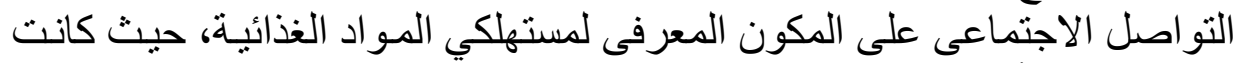

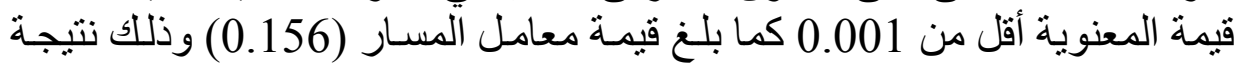

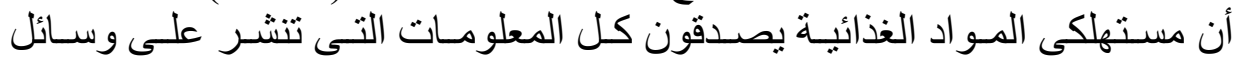

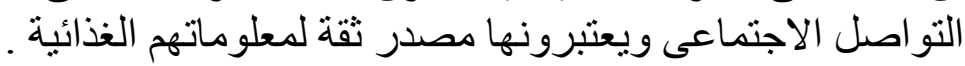

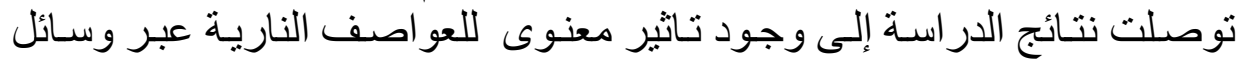

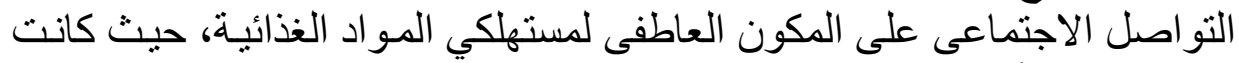

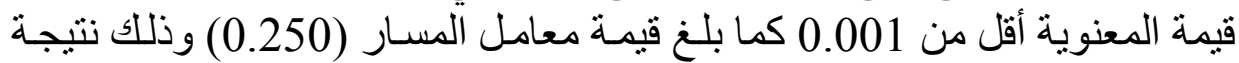

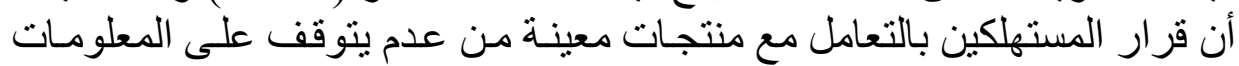

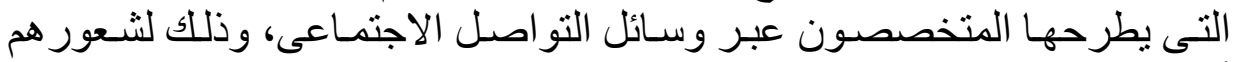

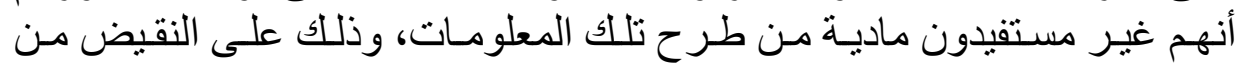

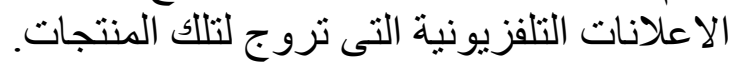

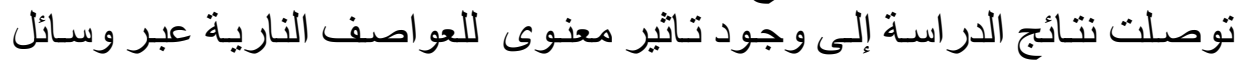

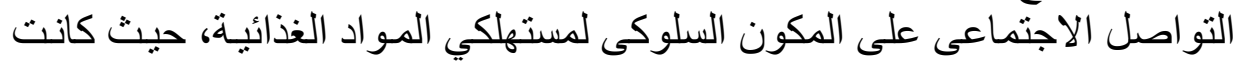

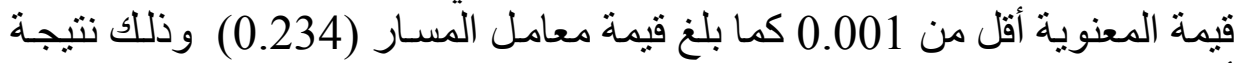

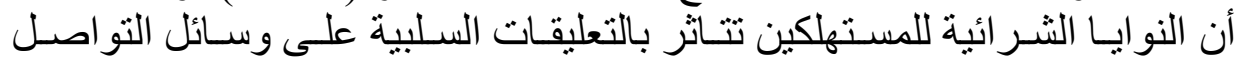

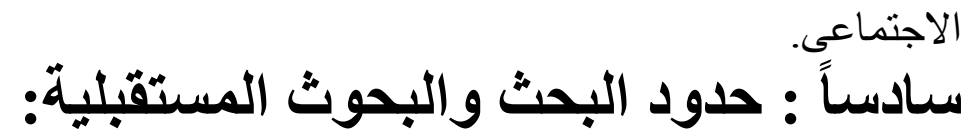

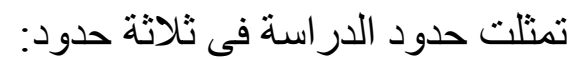

1- حدود مكانية: حيث اقتصر البحث على على تجميع البيانات إلكترونياً. 
2- حدود زمانية : حيث أقتصر البحث على تجميع البيانات إلكترونياً فى مدة

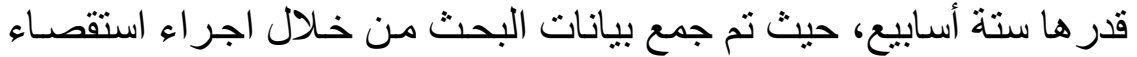

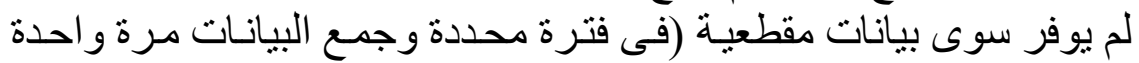
longitudinal cross sectional data لملاحظة التغير فى سلوك المستهلكين.

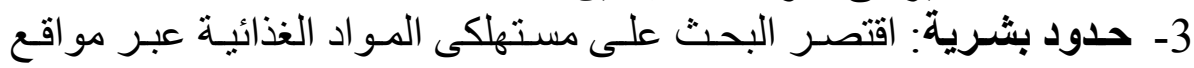

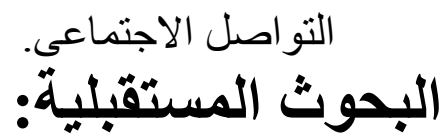

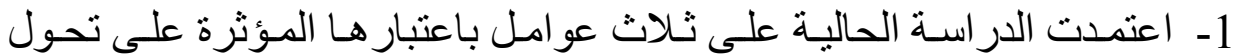

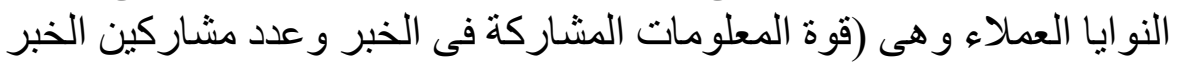

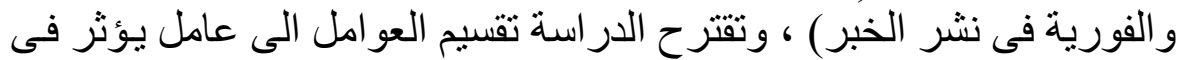

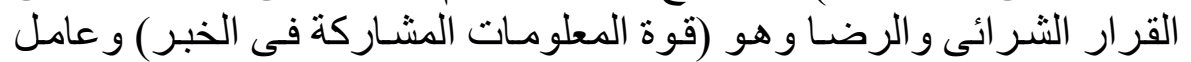
مؤثر فى ولاء المستهلك وهو (عدد مشاركين الخبر) و وعامل مؤثر في الكلمـة

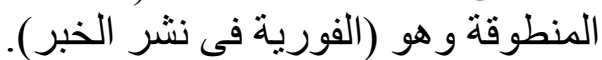

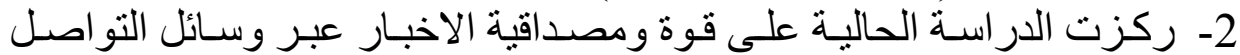

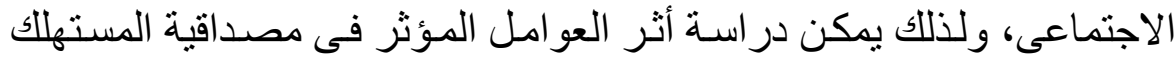
على اتجاهات المستهلك. ولأكن.

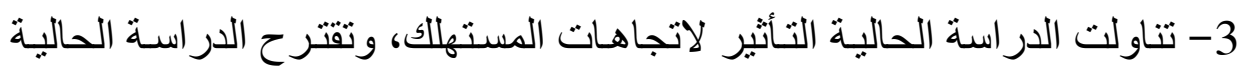

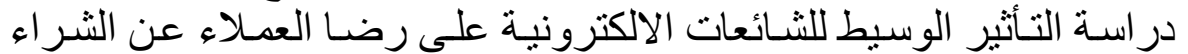
إلكترونيا و على السلوك الثرائر الثينى 


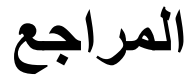

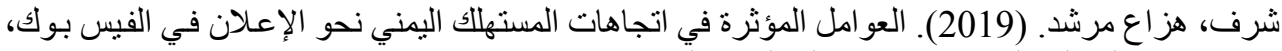

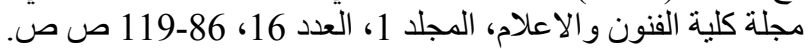

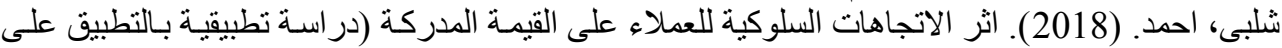

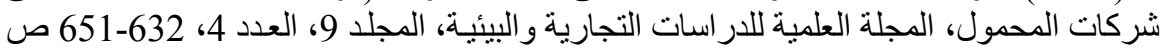

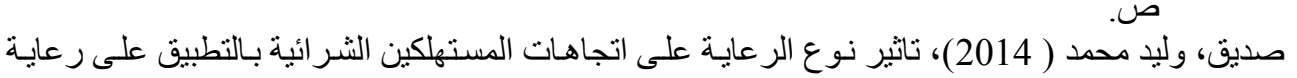

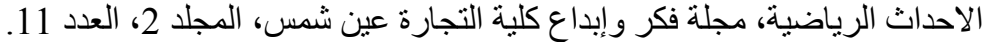

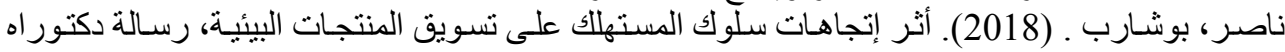

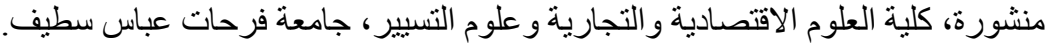

Amin, H., Rahman, A. R. A., Razak, D. A., \& Rizal, H. (2017). Consumer attitude and preference in the Islamic mortgage sector: a study of Malaysian consumers. Management Research Review.

Bachmann, A. K., Maran, T., Furtner, M., Brem, A., \& Welte, M. (2020). Improving entrepreneurial self-efficacy and the attitude towards starting a business venture. Review of Managerial Science, 1-21.

Bakar, R. M., Hidayati, N., \& Giffani, I. R. (2019). Apology and Compensation: Impact on Customer Forgiveness and Negative Word-of-Mouth (WOM). Jurnal Manajemen dan Kewirausahaan, 21(1).

Chawla, D., \& Joshi, H. (2019). Consumer attitude and intention to adopt mobile wallet in India-An empirical study. International Journal of Bank Marketing.

Chen, Y. F., Tsai, C. W., \& Chaung, Y. C. (2019). Influences of Online Negative Word of Mouth on Purchase Intention. International Journal of E-Adoption (IJEA), 11(1), 1-11.

Crisafulli, M. A., Von Holle, A., \& Bulik, C. M. (2008). Attitudes towards anorexia nervosa: The impact of framing on blame and stigma. International Journal of Eating Disorders, 41(4), 333-339.

D’Arco, M., Marino, V., \& Resciniti, R. (2019, June). How to (Not) Survive a Social Media Firestorm: The Dolce \& Gabbana's Ad Debacle in China. In International Conference on Advances in National Brand and Private Label Marketing (pp. 181-189). Springer, Cham.

Drasch, B., Huber, J., Panz, S., \& Probst, F. (2015). Detecting Online Firestorms in Social Media. In ICIS.

Ebner, T. (2014). "What is a Social Media Firestorm? A clear Checklist and Definition." Retrieved from http://www.socialmediafacts.net/firestorms/firestorm-definition(visited on $22 / 01 / 2019)$ 
Felix, R., Rauschnabel, P. A., \& Hinsch, C. (2017). Elements of strategic social media marketing: A holistic framework. Journal of Business Research, 70, 118-126.

Grégoire, Y., Salle, A., \& Tripp, T. M. (2015). Managing social media crises with your customers: The good, the bad, and the ugly. Business Horizons, 58(2), 173-182.

Gunasekara, G., Adams, A. A., \& Murata, K. (2017). Ripples down under: New Zealand youngsters' attitudes and conduct following Snowden. Journal of Information, Communication and Ethics in Society.

Hansen, N., Kupfer, A. K., \& Hennig-Thurau, T. (2018). Brand crises in the digital age: The short-and long-term effects of social media firestorms on consumers and brands. International Journal of Research in Marketing, 35(4), 557-574.

Huijuan, Y. (2019, May). Analysis of the Influence of Internet Negative Word-ofmouth on College Students' tourism Product Negative Purchase Intention. In 2019 4th International Conference on Social Sciences and Economic Development (ICSSED 2019). Atlantis Press.

Johnen, M., Jungblut, M., \& Ziegele, M. (2018). The digital outcry: What incites participation behavior in an online firestorm?. New Media \& Society, 20(9), 3140-3160.

Lamba, H., Malik, M. M., \& Pfeffer, J. (2015, August). A tempest in a teacup? Analyzing firestorms on twitter. In 2015 IEEE/ACM International Conference on Advances in Social Networks Analysis and Mining (ASONAM) (pp. 17-24). IEEE.

Luthans, F. (1992). Organizational behavior. New York: McGrawHill.

Mochalova, A., \& Nanopoulos, A. (2014). A targeted approach to viral marketing. Electronic Commerce Research and Applications, 13(4), 283-294.

Pfeffer, J., Zorbach, T., \& Carley, K.M. (2014). "Understanding online firestorms: Negative word-of-mouth dynamics in social media networks." Journal of Marketing Communications, 20(1-2), 117-128.

Rost, K., Stahel, L., \& Frey, B. S. (2016). Digital social norm enforcement: Online firestorms in social media. PLoS one, 11(6), e0155923.

Rouliez, P., Tojib, D., \& Tsarenko, Y. (2019). The influence of online review exposure on reviewers' intensity level of negative word of mouth. Journal of Hospitality \& Tourism Research, 43(5), 712-733.

schiffman.i. .kanuk (2016), Consumer behavior 4th edition. englewood cliffs newjersey

Shin, H. K., Hong, J. H., \& Kim, K. K. (2007). The Influence of Website Charateristics on Customer Satisfaction, Customer Loyalty, and 
Repurchase Intention in Internet Shopping Malls. The Journal of Society for e-Business Studies, 12(1), 41-71. 